NBER WORKING PAPER SERIES

\title{
DOES LEGALIZATION REDUCE BLACK MARKET ACTIVITY? EVIDENCE FROM A GLOBAL IVORY EXPERIMENT AND ELEPHANT POACHING DATA
}

\author{
Solomon Hsiang \\ Nitin Sekar \\ Working Paper 22314 \\ http://www.nber.org/papers/w22314 \\ NATIONAL BUREAU OF ECONOMIC RESEARCH \\ 1050 Massachusetts Avenue \\ Cambridge, MA 02138 \\ June 2016, Revised April 2019
}

We thank Scott Barrett, Julian Blanc, Ahimsa Campos-Arceiz, Christopher Costello, Jeremy Darrington, Andy Dobson, Ray Fisman, Martin Heijdra, Kelsey Jack, Amir Jina, Steven Levitt, Molly Lipscomb, Tom Milliken, Dinsha Mistree, Katarzyna Nowak, Michael Oppenheimer, Andrew Plantinga, Steven Raphael, Mary Rice, Shruti Suresh, Reed Walker, David Wilcove, Tom Vogl, and seminar participants at Columbia University, UC Berkeley, the UC Santa Barbara Occasional Conference, the NBER EEE meeting, and the Triangle Resources and Environmental Economics Seminar, for important comments and suggestions. N.S. was funded by a National Science Foundation Graduate Research Fellowship. The views expressed herein are those of the authors and do not necessarily reflect the views of the National Bureau of Economic Research.

NBER working papers are circulated for discussion and comment purposes. They have not been peer-reviewed or been subject to the review by the NBER Board of Directors that accompanies official NBER publications.

(C) 2016 by Solomon Hsiang and Nitin Sekar. All rights reserved. Short sections of text, not to exceed two paragraphs, may be quoted without explicit permission provided that full credit, including $\odot$ notice, is given to the source. 
Does Legalization Reduce Black Market Activity? Evidence from a Global Ivory Experiment and Elephant Poaching Data

Solomon Hsiang and Nitin Sekar

NBER Working Paper No. 22314

June 2016, Revised April 2019

JEL No. F18,F55,K42,O13,O17,Q2

\begin{abstract}
$\underline{\text { ABSTRACT }}$
Black markets are estimated to represent a fifth of global economic activity, but their response to policy is poorly understood because participants systematically hide their actions. It is widely hypothesized that relaxing trade bans in illegal goods allows legal supplies to competitively displace illegal supplies, but a richer economic theory provides more ambiguous predictions. Here we evaluate the first major global legalization experiment in an internationally banned market, where a monitoring system established before the experiment enables us to observe the behavior of illegal suppliers before and after. International trade of ivory was banned in 1989, with global elephant poaching data collected by field researchers since 2003 . A one-time legal sale of ivory stocks to China and Japan in 2008 was designed as an experiment, but its global impact has not been evaluated. We find that international announcement of the legal ivory sale corresponds with an abrupt $\sim 66 \%$ increase in illegal ivory production across two continents, and a possible ten-fold increase in its trend. An estimated $\sim 71 \%$ increase in ivory smuggling out of Africa corroborates this finding, while corresponding patterns are absent from natural elephant mortality, Chinese purchases of other precious materials, poaching of other species, and alternative explanatory variables. These data suggest the widely documented recent increase in elephant poaching likely originated with the legal sale. More generally, these results suggest that changes to producer costs and/or consumer demand induced by legal sales can have larger effects than displacement of illegal production in some global black markets, implying that partial legalization of banned goods does not necessarily reduce black market activity.
\end{abstract}

\author{
Solomon Hsiang \\ Goldman School of Public Policy \\ University of California, Berkeley \\ 2607 Hearst Avenue \\ Berkeley, CA 94720-7320 \\ and NBER \\ shsiang@berkeley.edu \\ Nitin Sekar \\ Princeton University \\ 106A Guyot Hall \\ Princeton, NJ 08544-2016 \\ nitin.sekar@gmail.com
}




\section{Introduction}

Governments frequently endeavor to ban the trade of products and services-like certain drugs, artifacts, weapons, endangered species, gambling, human organs, abortions, or prostitution-deemed to have unfavorable consequences for individuals or society at large. The black markets that emerge in response to these bans often produce harmful externalities, a fact that regularly generates debate as to whether legalization may increase social welfare overall (Becker, 1968; MacCoun and Reuter, 2001). Basic economic intuition suggests that legalizing a regulated supply of a banned good by creating a "white market" is preferable to an outright ban if the legal supply generates fewer externalities and can crowd out the illegal supply via competition in the marketplace (Kremer and Morcom, 2000; Becker, Murphy, and Grossman, 2006). Importantly, this standard model assumes that supply and demand in black markets does not change when white markets are created - an assumption that may not hold in many contexts. If the creation of a white market makes smuggling and black market trade easier, perhaps because illegal supplies can masquerade as legal, then the cost of illegal production will fall. Further, if legalization reduces stigma associated with consumption of the banned good, perhaps because legal status or the visibility of peer consumption alters norms, then black market demand may increase when a white market is formed. Thus, determining the overall net effect of legalization on black market activity requires that we understand whether these supply and demand effects, both of which are likely to increase black market activity, are outweighed by the competitive displacement of illegal supplies by legal ones. Because the sign of this net effect is theoretically ambiguous, its determination is ultimately an empirical question.

Empirically identifying linkages between white and black markets is fundamentally difficult because the actions of illegal producers and consumers are intentionally hidden. Usually, when a product is banned, its production and trade move underground, preventing observers from accessing the economic data that would allow us to identify the net effect of legalization experiments on black market activities. However, ivory markets and elephant poaching represents a unique opportunity that we exploit to address this question empirically. When raw ivory is produced illegally by harvesting the tusks of unlawfully killed elephants, the carcasses of these animals are left behind by the poachers, leaving a record of illegal production. Ecologists have systematically collected data on these carcasses through a global network of field scientists (CITES Standing Committee, 2012). We use these data to observe the effect of a one-time legal international sale of ivory that was unexpectedly announced in 2008, in an environment where international trade in elephant ivory had been banned by international treaty since 1989. The abrupt and singular nature of this legal sale allows us to employ an event study design (Kothari and Warner, 2006) to identify its causal effect on the global underground network of primary suppliers.

Over and above the properties that make it uniquely amenable to econometric analysis, the 2008 legal international sale of ivory is an interesting event to study because it was motivated by basic economic arguments and framed as "experimental," although to our knowledge the results of this global economic experiment have never been systematically evaluated by economists. At the time when the sale was proposed, it was unknown and widely debated whether legal supplies would be effective in competitively displacing illegal suppliers (Barbier et al., 2009). An earlier legal sale had occurred in 1999, based on the same economic arguments, but baseline data on poaching rates did not 
exist so it was impossible to measure the effect of this event. To address this oversight, the Convention on the International Trade of Endangered Species (CITES) established field sites throughout Africa and Asia to monitor poaching rates with the hope of identifying effects of possible future sales - the monitoring network that we leverage in this analysis. Thus, the legal sale we analyze here represents a grand economic experiment in global black market dynamics in which testable economic hypotheses were announced in advance and a systematic international data collection system was put in place to measure its outcome.

Product bans have been analyzed in economics at least since the work of Becker (1968), although theoretical models dominate the analysis because the quasi-experimental or experimental conditions needed for causal inference are rare and often unethical (MacCoun and Reuter, 2001; Levitt and Miles, 2006). In theoretical analyses, the idea that legal supplies will competitively displace illegal supplies following legalization is usually taken as self-evident (e.g. Bergstrom (1990)), so prior theoretical work has focused on the merits and flaws of bans in the presence of uncertainty (Weitzman, 1974), institutional constraints (Kremer and Morcom, 2000), enforcement costs (Glaeser and Shleifer, 2001), and limited government resources (Becker, Murphy, and Grossman, 2006). Our work here suggests that the magnitude and importance of competitive displacement may not always be as substantial as has been historically thought. First, one unit of legal sales need not necessarily displace one unit of illegal sales, as is generally assumed, because legal and illegal versions of otherwise physically identical goods may be treated by consumers as different products that are not perfect substitutes, leading to separation of black and white markets. This idea can explain why legal versions of a good may command a premium relative to illegal versions, even in cases when illegal consumers bear essentially no risk of prosecution and illegal supplies bear a substantial risk. ${ }^{1}$ Second, the presence of a white market may interact directly with supply, by masking illegal trades, or demand, by reducing social stigma or fear of penalties. Both of these effects would offset some competitive displacement, perhaps even dominating it in some contexts, leading to perverse consequences. Notably, the supply and demand effects have opposing influence on black market prices, leading to predictions more ambiguous than the standard argument that legalization necessarily depresses black market prices. The unique properties of illicit ivory production allow us to provide the first empirical evidence that competitive displacement may be small relative to these other responses in a global black market. Of course, numerical values from our empirical estimates cannot be directly applied to other markets since marketspecific elasticities govern these behaviors, but the insight that illegal production need not decline in response to legalization is generalizable.

In addition to providing new insight into the nature of linkages between black and white markets, our analysis advances how ideas from the economics of crime literature can be used in the management of global environmental resources. Economic principles are increasingly used to advance our understanding of and success in resource management, often by transplanting economic insights from economic subfields far afield from traditional resource economics. For example, Nordhaus (1993) used insights from optimal growth theory to demonstrate that global greenhouse gas emissions should be mitigated gradually; Costello, Gaines, and Lynham (2008) demonstrated how successful tradable permits are at slowing the decline of fisheries; Barrett (1994) demonstrated the utility of using game

\footnotetext{
${ }^{1}$ For examples, consider perfectly imitated counterfeit products (such as DVDs or handbags) sold for a discount on the street; or uncertified taxi cabs offering low cost rides from an airport.
} 
theoretic models to understand environmental treaty design; and Burgess et al. (2012) showed the importance of accounting for political competition in the management of forests. We incorporate ideas from Becker (1968) and others in the economics of crime literature (Levitt, 2003) to the problem of managing natural resources at risk of being harvested illegally. ${ }^{2}$

The structure of the paper is as follows. In Section 2 we describe the context of banned ivory trade and the 2008-2009 legal sale. In Section 3 we augment standard economic theory to account for possible supply and demand effects. In Section 4 we describe our data. In Section 5 we describe our empirical strategy and detail the timing of events, as the abrupt nature of the sale announcement is critical for our research design. In Section 6 we present our main results describing the response of poaching to the legal sale, along with robustness checks and corroborating evidence using data on seizures of ivory contraband. In Section 7 we test for violations of the assumptions underpinning our event study design, informed by alternative theories in the literature. We conclude in Section 8 .

\section{The ivory trade ban and legal sale}

In 1989, to protect declining wild African elephant (Loxodonta africana) populations, CITES banned all international trade of ivory, with regulation of domestic trade in ivory left to national governments. Poaching continued but slowed markedly for several years, resulting in a recovery of many elephant populations (Stiles, 2004; Lemieux and Clarke, 2009).

By the mid-1990s, elephant poaching had begun to climb again, possibly due to rising demand from economically empowered Asia (Khanna and Harford, 1996). Numerous analysts suggested that governments could sell their own legal stockpiles of ivory - collected from elephants that died naturally - to Asian buyers, with the goal of competitively displacing black market ivory sales (Kremer and Morcom, 2000; Stiles, 2004).

Opponents of legal ivory sales warned that a one-off sale could lead to a substantial increase - not decrease - in the poaching of elephants (International Fund for Animal Welfare, 2006; The Economist, 2008). These advocates generally voiced two concerns. First, when a ban exists, it suppresses demand since some potential consumers are unlikely to buy banned substances (Becker, Murphy, and Grossman, 2006; Heltberg, 2001), perhaps due to social stigma or fear of punishment. Easing bans may thus bring these consumers back into the market (Sullivan, 2007). Since legal supplies of ivory would be limited, this increased demand could spill over into the black market, especially if consumers have difficulty distinguishing legal and illegal versions of the same good. Secondly, relaxing a ban may make it more difficult for authorities to distinguish illegal ivory from legal versions (International Fund for Animal Welfare, 2006; CITES, 2002b), lowering the costs of smuggling or selling illegal ivory and thus increasing supply at a given price. We formalize these arguments in the next section.

Convinced by the intuition of competitive displacement, CITES approved a single legal sale of ivory to Japan in 1999. Since Botswana, Namibia, and Zimbabwe had maintained healthy wild elephant populations, CITES designated these countries as eligible to sell their legal ivory stockpiles internationally; in negotiations, the sale was framed as a side-payment designed to reward strong

\footnotetext{
${ }^{2}$ The relevance of our findings are underscored by current proposals to stem poaching by allowing legal sales of rhinoceros horn (Biggs et al., 2013) and tiger products (Abbott and van Kooten, 2010) or to promote the production of synthetic animal products, such as synthetic shark fins (Potter and Farr, 2015) or rhinoceros horn (Staedter, 2015).
} 
anti-poaching efforts. However, since no data collection system existed prior to the sale, the effects of the sale on poaching were essentially unmonitored. To correct this, in anticipation of possible future sales, CITES established the Monitoring the Illegal Killing of Elephants (MIKE) program to track the severity of poaching across 79 sites throughout Africa and Asia. Primary data collection began in mid-2002 and focused heavily on the construction of a poaching index Proportion of Illegally Killed Elephants (PIKE), equal to the fraction of detected elephant carcasses that were illegally killed (Burn, Underwood, and Blanc, 2011; CITES Standing Committee, 2012).

Then China, a major market for illegal ivory (Martin and Stiles, 2003; Milliken, Burn, and Sangalakula, 2007), joined Japan in requesting the right to purchase ivory legally in a one-time sale (International Fund for Animal Welfare, 2006; CITES Standing Committee, 2008a); opponents stated that China's regulatory system was not stringent enough to prevent the conflation of legal and illegal ivory (International Fund for Animal Welfare, 2006). Proponents argued that competitive displacement was likely powerful enough of a market force to justify a second legal sale. For example The Economist (2008) ran an editorial stating

"A fresh supply of legal ivory may depress the price, and reduce the incentive to poach.... For doctrinaire types, who oppose all trade in ivory, the forthcoming sale is not just a challenge to endangered animals; it could be a threat to the credibility of their best-loved arguments."

In July 2008, after years of debate (CITES Standing Committee, 2008a, 2005a, 2007c), CITES announced that China would join Japan as the second approved trading partner for legal ivory and declared that an experimental sale may proceed (CITES Standing Committee, 2008a,b). Botswana, Namibia, and Zimbabwe (this time with South Africa) were again permitted to sell a limited quantity of stockpiled ivory that had either been collected from elephants that died naturally or were killed during animal control measures. In October-November of 2008, China and Japan purchased 62 and 45 tons of ivory, respectively, at auction from the approved sellers ${ }^{3}$ (CITES Standing Committee, 2009; Milliken et al., 2013). In March-April of 2009, the shipment of legal African ivory arrived in China and Japan (CITES Standing Committee, 2009), where the governments of the two nations are monopolists for new legal ivory in their respective domestic markets, gradually reselling the ivory to artisans and citizens via networks of government retailers. At present, neither of the purchased stockpiles has been completely sold off to the public.

\section{Theoretical framework}

\section{Separation of black and white markets}

Many economic models that consider legalization of banned goods implicitly assume that legal and illegal versions of a good are perfect substitutes (Becker, 1968; Bergstrom, 1990; Kremer and Morcom, 2000; Glaeser and Shleifer, 2001; Levitt, 2003). We begin by pointing out that black and white

\footnotetext{
${ }^{3}$ Christy (2012) reported that since the Japanese used mostly medium-size, high-quality tusks for their traditional hanko seals, and the Chinese preferred large whole tusks for their art work, the two countries colluded with each bidding only on one type of ivory, causing auction prices to be low.
} 
A

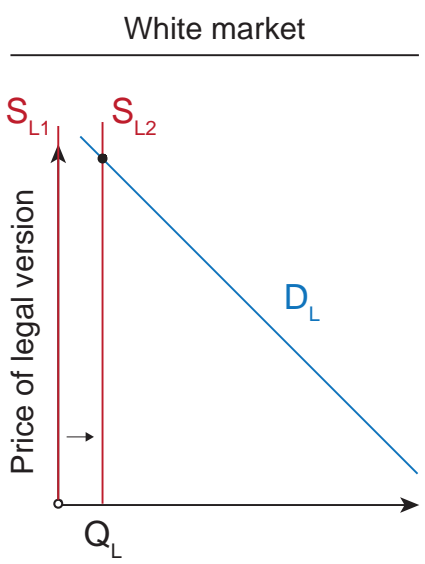

Quantity of legal version

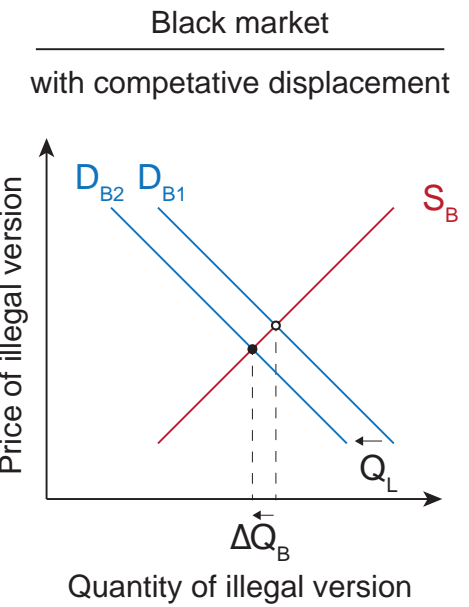

Quantity of illegal version
B

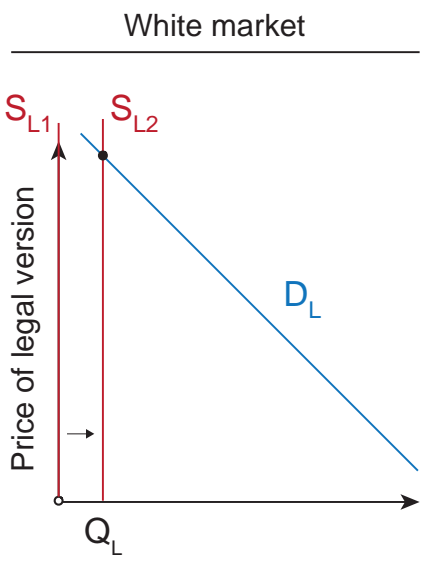

Quantity of legal version

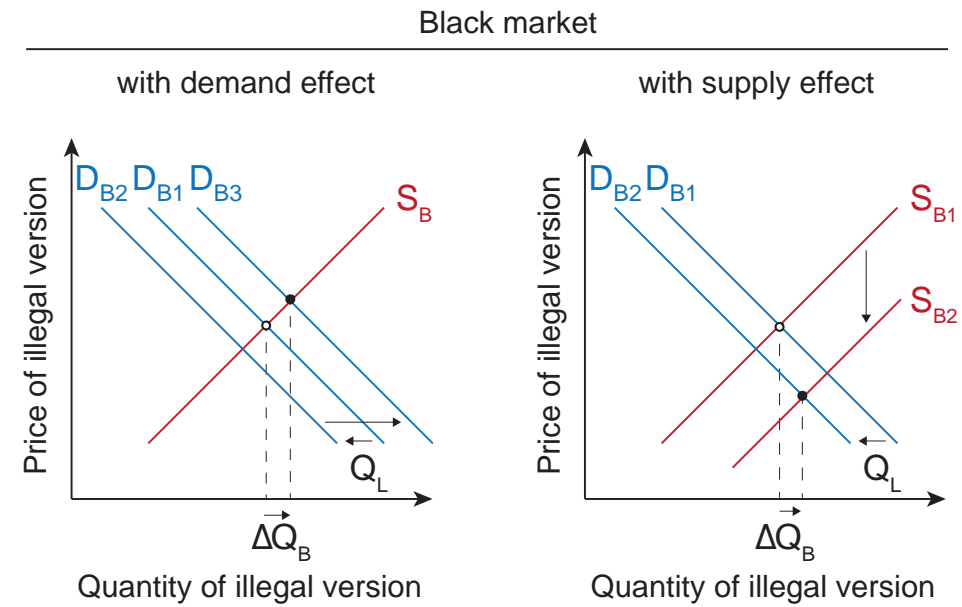

Figure 1: Linkages between black and white markets. Supply (red) and demand (blue) functions in legal white markets (left) and corresponding banned black markets (right). The initial equilibria are marked by the open circles. Then a sale of $Q_{L}$ units of the legal version of the good occurs in the white market. The final equilibrium is marked by the closed circle. The net change in sales of the illegal version is $\Delta Q_{B}$. (A) Traditional theory suggests supply and demand do not respond to legalization directly; only that black market demand shifts inward by $Q_{L}$ from $D_{B 1}$ to $D_{B 2}$, reducing illegal production and lowering prices. Black and white market prices need not equalize. (B) If legalization directly increases demand, for example because social stigma associated with consuming illegal versions of a good have decreased, then the demand function in the black market may shift outward to $D_{B 3}$, which could exceed initial demand even in the presence of competitive displacement. If legalization lowers the cost of supplying illegal versions of the good, for example because smuggling may become easier, then the supply function will shift downward from $S_{B 1}$ to $S_{B 2}$, causing production to rise as prices fall. In the presence of competitive displacement, the net effect on production $\Delta Q_{B}$ and prices is ambiguous. Demand effects and supply effects may happen simultaneously but are drawn separately for clarity. 
markets for the same product are closely linked, but are separate markets. One attribute of goods that consumers may value is the process that produced the good, even if the physical nature of the product that is provided to the buyer is identical to that of another product. Kosher or Halal meat, dolphinsafe tuna, conflict-free diamonds, free-trade coffee, and imported bottled waters are all products that command a premium to consumers relative to other products that might be indistinguishable on physical or chemical grounds alone, since the origin of the product matters to consumers. Similarly, legal and illegal versions of a banned good should be considered different products which may exhibit different demand functions and prices in equilibrium.

Let $S_{B}$ and $D_{B}$ be the quantity supplied and demanded in the black market, while $S_{L}$ and $D_{L}$ supply and demand in the legal white market. $P_{B}$ and $P_{L}$ are equilibrium prices in the two markets. Prior to any legalization, the legal supply is constrained to zero by definition and $P_{L}$ is undefined, as shown in Figure 1A. Following a legal sale of fixed size $Q_{L}$, as in the ivory case, the white market supply shifts outwards and satisfies legal demand up to the quantity $Q_{L}$. Under the theory of competitive displacement, this shifts black market demand inward by $Q_{L}$ since consumers of the legal product need not also consume the illegal version of the good. Prices in the black market fall, and equilibrium production falls ${ }^{4}$ by $\Delta Q_{B}$, where

$$
\Delta Q_{B}=-Q_{L} \frac{\partial S_{B}}{\partial P_{B}}\left(\frac{\partial S_{B}}{\partial P_{B}}-\frac{\partial D_{B}}{\partial P_{B}}\right)^{-1}
$$

So long as the supply curve is upward sloping and the demand curve is downward sloping, $\Delta Q_{B}$ will be negative and legal supply will competitively displace some illegal supply. In contrast to models where legal and illegal versions of the good are identical, the reduction in illegal production is weakly less than the quantity sold legally

$$
Q_{L} \geq-\Delta Q_{B}
$$

with the value for $\Delta Q_{B}$ depends on the slope of the supply and demand functions. If illegal supply is inelastic $\left(\frac{\partial S_{B}}{\partial P_{B}}=0\right)$ then $\Delta Q_{B}=0$ regardless of $Q_{L}$. If black market supply is perfectly elastic $\left(\frac{\partial S_{B}}{\partial P_{B}} \rightarrow \infty\right)$ or black market demand is inelastic $\left(\frac{\partial D_{B}}{\partial P_{B}}=0\right)$, then full displacement occurs since $\Delta Q_{B}=-Q_{L}$. However these extreme conditions seem rare, so we would likely expect that selling 100 $\mathrm{kg}$ of legal ivory should reduce illegal production by less than $100 \mathrm{~kg}$.

Note that physically identical products have different prices in the black vs white market. In general, if legal sales are relatively small compared to black market quantities, we might expect a "white market premium" where $P_{L}>P_{B}$, as in Figure 1A, although "black market premiums" $\left(P_{L}<P_{B}\right)$ are also theoretically possible depending on the structure of $D_{L}$ and the size of the legal sale. ${ }^{5}$ Some analysts have argued that competitive displacement of illegal ivory after the legal ivory sale was limited because China and Japan set their domestic prices for legal ivory too high, but a naturally high legal price may be consistent with the existence of separate black and white markets and does not determine the magnitude of $\Delta Q_{B}$ (Eq. 1).

\footnotetext{
${ }^{4} \Delta Q_{B}$ is obtained by solving for the horizontal displacement in the equilibrium black market quantity in Figure $1 \mathrm{~A}$.

${ }^{5}$ Positive black market premiums $\left(P_{B}-P_{L}>0\right)$ might not occur even if illegal suppliers face risk of prosecution. The burden of legal risks will be captured in the shape of $S_{B}$ and $D_{B}$ and their existence need not imply $P_{L}<P_{B}$.
} 


\section{Black market supply and demand effects of legalization}

We now expand the "standard model" of competitive displacement to account for the fact that legalization may interact directly with supply and demand. These simple adjustments render the predictions of legalization more ambiguous.

First consider black market supply. When legal versions of a good are introduced to a market, it may become easier to smuggle or trade illegal versions of the good, since illegal versions may masquerade as legal versions. This "masking effect" will increase the costs of law enforcement, consistent with intuition presented by Glaeser and Shleifer (2001), and lower the costs of supplying illegal versions of the good as the risk of getting caught falls, similar to findings in Kuziemko and Levitt (2004). Masking occurs, for example, when legal brothels are used to hide human trafficking in the sex industry (Sullivan, 2007). Because a larger legal presence of a good lowers the cost of supplying the black market, we write masking as the condition

$$
\frac{\partial S_{B}}{\partial Q_{L}}>0
$$

since a lower supply cost will raise supply for any given price. In the context of the legal ivory sale, there is evidence that masking altered costs in the black market supply chain - for example Christy (2012) wrote,

"[In China,] any [legal] ivory carving larger than a trinket must have a photo ID card. But criminals have turned the ID-card system into a smuggling tool. In the ID cards' tiny photographs, carvings with similar religious and traditional motifs all look alike... [I]vory dealers in China are selling ivory carvings but retaining their ID cards to legitimize carvings made from smuggled ivory. The cards themselves now have value and are tradable in a secondary market."

Next consider black market demand. The notion of competitive displacement suggests black market demand should fall because some demand is satisfied in the legal market, however demand could also rise if new consumers are brought into the market when legalization occurs. This could occur if observable legal consumption alters social norms so that stigma associated with consuming illegal versions of the good falls. It also might occur occur if the risk of legal penalty for consuming the illegal good falls, due to masking on the supply side. Finally, it might also be the case that consumers misunderstand which versions of a good are legal vs. illegal, and they participate as consumers in the black market by mistake. All of these effects suggest

$$
\frac{\partial D_{B}}{\partial Q_{L}}>0
$$

where the differential accounts only for these direct effects on demand and not for any displacement effects. In the context of the legal ivory sale, there is some indication that this demand effect plays a role. For example, a Chinese newspaper (Qilu Weekly, January 25, 2014) stated that the sale "stimulated new consumption instead of slowing down illegal ivory trades," and the executive director of the Environmental Investigation Agency argued that "allowing many tonnes of ivory to enter the marketplace with CITES' blessing has served only to boost the illegal trade, confusing consumers as to whether ivory is legal or illegal. Far from satisfying demand, the increased availability of ivory... 
has only spurred consumer appetite" (Rice, 2012). Some of this demand response may have been due to marketing; for example, after the sale, Chinese state television reported ivory to be a legitimate investment which should exhibit sustained high prices (CCTV.com, 2011). Since it is important to the case of ivory, we also note that if observing legal consumption of a good drives demand for the illegal counterpart, then the durability of the good is important ${ }^{6}$ because more individuals may observe the good's consumption the longer it circulates in the market. For example, a legal ivory amulet will be observed by a growing number of people the longer its owner wears it, potentially generating greater demand over time.

The presence of direct supply and demand effects, as described by Eq. 2-3, has important implications when considering the effects of legalization. Critically, the sign of supply and demand effects suggest they both increase black market production and sales, as illustrated in Figure 1B. These two effects will be superimposed on whatever competitive displacement occurs, such that the total change in black market production caused by the legal sale is

$$
\Delta Q_{B}=(\underbrace{-\frac{\partial S_{B}}{\partial P_{B}}}_{\begin{array}{c}
\text { Displacement } \\
\text { effect } \\
(-)
\end{array}}+\underbrace{\frac{\partial D_{B}}{\partial Q_{L}} \frac{\partial S_{B}}{\partial P_{B}}}_{\begin{array}{c}
\text { Demand } \\
\text { effect } \\
(+)
\end{array}}-\underbrace{\frac{\partial S_{B}}{\partial Q_{L}} \frac{\partial D_{B}}{\partial P_{B}}}_{\begin{array}{c}
\text { Supply } \\
\text { effect } \\
(+)
\end{array}}) \frac{Q_{L}}{\frac{\partial S_{B}}{\partial P_{B}}-\frac{\partial D_{B}}{\partial P_{B}}}
$$

which has an unknown sign that depends on the price elasticities of black market supply and demand, as well as their elasticity with respect to legal sales. ${ }^{7}$ Thus it is not obvious a priori that legalization should reduce black market activity and determining the sign of the effect in Eq. 4 is ultimately an empirical question.

\section{Prices}

A final observation worth noting is that falling or stationary black market prices following legalization provide limited information on the sign of of $\Delta Q_{B}$ and does not indicate whether competitive displacement has occurred. Across various contexts, authors have argued incorrectly that falling prices after a legalization event indicate successful competitive displacement. Falling prices could be driven entirely by the supply effect, which would lead to increasing illegal production in the absence of other effects. Concurrent supply effects and competitive displacement would also depress prices but could have an effect of any sign on illegal production. Furthermore, prices may remain unchanged if the influence of changing supply and demand on prices offset one another, preventing us from distinguishing $\Delta Q_{B}=0$ and $\Delta Q_{B}>0$ using price data alone. The only thing we conclude for sure from prices is that if they rise, illegal production is also rising due to demand effects. Thus, instead of focusing on price data, as previous authors have and which provides indeterminate findings, we directly examine the response of producers via poaching records.

\footnotetext{
${ }^{6}$ Kremer and Morcom (2000) also argue that the durability of ivory is important to consider because it allows ivory to be stored and stockpiled, allowing for strategic dynamic behavior.

${ }^{7}$ Note that in this linear model, the quantity of a legal good that is sold does not influence the sign of its effect on black market activity. This result contrasts to arguments by some analysts that the legal sale of ivory was ineffective at slowing poaching because it was "too small" and not enough legal ivory was sold.
} 


\section{Data}

In our primary analysis, we analyze poaching data to understand the behavior of black market producers. We then use data on seizures of contraband, mostly from smugglers, to corroborate our main results. We conclude by testing that data on key covariates do not exhibit counfounding discontinuities across the data of the legal sale.

\section{Poaching data}

We obtain data on the standard poaching measure, the proportion illegally killed elephants (PIKE), from the Monitoring the Illegal Killing of Elephants (MIKE) program which tracks the severity of poaching across 79 sites in 40 African and Asian countries beginning in 2002 (Burn, Underwood, and Blanc, 2011; CITES Standing Committee, 2012). The data describe the count of elephant carcasses from illegal killings that are discovered by field researchers who regularly survey each site.

The PIKE index is a widely used normalization of this count data, where the count of illegal killings is divided by the total number of elephant carcasses discovered by the field workers, including those that died of natural causes or were killed legally:

$$
P I K E_{i j t}=\frac{\text { illegal_carcasses }_{i j t}}{\text { legal_mortality }_{i j t}+\text { illegal_carcasses }_{i j t}}
$$

where $i$ indexes sites in country $j$ and $t$ indexes years. This normalization is widely adopted by the ecology community because it removes trends due to changing elephant populations or to idiosyncratic changes in surveyor effort or behavior. ${ }^{8}$ We follow the extensive ecological literature analyzing poaching

${ }^{8}$ To see this, observe that for any period at a given site, the total count of illegal carcasses and total carcasses (illegal plus legal) are

$$
\begin{aligned}
& \text { illegal_carcasses }=\text { population } \times \operatorname{Pr}(\text { illegal_death }) \times \operatorname{Pr}(\text { discovery } \mid \text { death }) \\
& \text { total_carcasses }=\text { population } \times \operatorname{Pr}(\text { death }) \times \operatorname{Pr}(\text { discovery } \mid \text { death })
\end{aligned}
$$

where death and discovery conditional on death can be thought of as (possibly inhomogenous) Bernoulli processes for each elephant. Search effort and behavior of field workers will affect the probability of discovery in some unknown way

$$
\operatorname{Pr}(\text { discovery } \mid \text { death })=f(\text { search_effort })
$$

that is unobservable. PIKE is thus

$$
\begin{aligned}
P I K E & =\frac{\text { illegal_carcasses }}{\text { total_carcasses }} \\
& =\frac{\text { population } \times \operatorname{Pr}(\text { illegal_death }) \times f(\text { search_effort })}{\text { population } \times \operatorname{Pr}(\text { death }) \times f(\text { search_effort })} \\
& =\frac{\operatorname{Pr}(\text { illegal_death })}{\operatorname{Pr}(\text { death })} \\
& =\frac{\operatorname{Pr}(\text { illegal_death })}{\operatorname{Pr}(\text { illegal_death })+\operatorname{Pr}(\text { legal_death })}
\end{aligned}
$$

which has been purged of the influence of unobservable changes in population and surveyor behavior. An alternative measure

$$
\frac{\text { illegal_carcasses }}{\text { legal_carcasses }}=\frac{\operatorname{Pr}(\text { illegal_death })}{\operatorname{Pr}(\text { legal_death })}
$$

also removes the influence of these two factors, but has the undesirable property of approaching infinity when the number of legal carcasses discovered becomes small. In our sample, many sites report zero legal carcasses in many periods. We adopt the PIKE measure because it is the standard measure used in the analysis of elephant poaching, however we also check that our results are not driven by the form of this index by estimating models using the (log) count of illegal carcasses as a dependant variable, flexibly controlling for the count of legal carcasses discovered in each site-period. 
data by using site-level PIKE data, although we also employ a variety of checks and alternative models to ensure our results are not driven by changing numbers of legal elephant deaths or by the specific structure of the PIKE index. We note that even though PIKE is bounded between zero and one, once conditioned on fixed effects (as described below), the PIKE data are essentially normally distributed (see Data Appendix). PIKE includes data from African savanna elephant (Loxodonta africana), African forest elephant (Loxodonta africana cyclotis), and Asian elephant (Elephas maximus) range countries.

We use all publicly available annual PIKE data from 2003 until 2013 (CITES MIKE, accessed 25-4-2015). We omit data from 2002, the first year of data collection, because data collection began late at most sites reporting in that year, making it incomparable to later years, and the distribution of 2002 data exhibits numerous irregularities relative to all following years. We also drop three site-byyear observations that were outliers $(>9 \sigma)$ in natural mortality due to natural events (e.g. droughts). Six observations with zero total carcasses are assigned PIKE $=0$ (otherwise PIKE $=\frac{0}{0}$ ). We drop two observations from sites that reported PIKE only one year in this remaining sample, since changes over time within these sites cannot be identified. This leaves us with 562 PIKE observations in an unbalanced panel across 77 sites in 38 countries.

Annually aggregated PIKE data is made publicly available by CITES, although monthly data exists but is not made public. We requested the monthly PIKE data from CITES multiple times, which would have allowed us to more precisely determine the timing of changes in poaching and adjust for seasonality, but were not permitted access to the data due to the structure of legal agreements between CITES and the elephant range states that collect the data.

We use official CITES data published on Github.com ${ }^{9}$ as well as published CITES reports (CITES, 2012, 2014). However, in our analysis we discovered 18 site-year observations where these two data sources disagree. CITES did not respond to repeated requests ${ }^{10}$ to clarify which data source is correct, so we run our main analysis on both data sources and find our results are robust to these discrepancies.

See the Appendix for additional details and documentation on all of the above issues.

\section{Data on seizures of contraband ivory}

The Elephant Trade Information System (ETIS) provides the world's largest collection of ivory seizure records (Milliken et al., 2013), with data as far back as 1989. We used data on the number of seizures made globally that was available from June 26, 2012, when analysis for the 16th CITES Conference of Parties was conducted (Milliken, personal communication). In addition, we obtain data on the weight of ivory seizures in each country-by-year from 1996 to $2011^{11}$ (Underwood, Burn, and Milliken, 2013).

Increases in seizures of ivory are thought to correspond with an increase in ivory smuggling activity, although these data are known to be partially confounded by changing surveillance effort by

\footnotetext{
${ }^{9}$ CITES made an Excel file of the official PIKE data (for 2002-2011) available through a Github site (https://Github.com/citesmike/mike_R_analyses/blob/master/pike_sc62.csv); this data was originally accessed May 7, 2013 and appears unchanged as recently as April 25, 2015.

${ }^{10}$ Requests were made on July 8, 2014, July 21, 2014, and August 18, 2014 by both email and phone.

${ }^{11}$ We lack the ideal data set containing exact weight of seized ivory in each country-year, but we can estimate these values by by combining two available data sets: (i) the year and exact weight (but not the country) of each seizure made between 1996 and 2011, and (ii) the count of small (less than $10 \mathrm{~kg}$ ), medium (between $10 \mathrm{~kg}$ and $100 \mathrm{~kg}$ ), and large (100 $\mathrm{kg}$ or greater) seizures made in each country in each year. Using data from (i), we calculated the weight of an average small, medium, and large seizure made each year; we then multiplied these averages by the count of seizures made in each size class in each country each year from (ii); we then sum these values within each country-year to estimate the total weight of ivory seizures.
} 
law enforcement - which is unobserved - so these data are relied on only as providing corroborating evidence (Wasser et al., 2010; Christy, 2012; Nowak et al., 2013).

\section{Covariates}

We obtain data on potential covariates measuring Chinese influence and presence in elephant range states from a variety of sources. We used GDP data from the World Bank's World DataBank (World Bank, 2013). For data on exports from and imports to elephant range states, we use the International Monetary Fund's Direction of Trade Statistics, taken from IHS Global Insight Web (IHS Global Insight, 2013). We used estimates of Chinese ODA-like (Overseas Development Assistance) and OOF-like (Other Official Flows) investments in African range states from AidData.org (Strange et al., 2013b,a). For Japan's aid to elephant range states, we used total official flows (sum of ODA and OOF) from the OECD website (OECD, 2013). Estimates of Chinese foreign direct investment were taken from the "actually used foreign direct and other investment"sections in Chinese Statistical Yearbooks 20022012 (China Statistics Press, 2012b; All China Data Center, 2013). We obtain the number of Chinese personnel in each elephant range state at year's end for labor services and engineering projects from the China Trade and External Economic Statistical Yearbooks 2006 (China Statistics Press, 2006), 2009 (China Statistics Press, 2009), 2012 (China Statistics Press, 2012a) as a measure of the physical presence of Chinese citizens in countries reporting PIKE. We have no reason to believe any potential bias from this data, whether from press reports (Strange et al., 2013b,a) or China's self-reported statistics (China Statistics Press, 2012b; All China Data Center, 2013; China Statistics Press, 2006, 2009, 2012a), would affect our ability to find patterns in these data relevant to this analysis. In response to the possibility that some phenomenon other than the legal sale might have led to a spike in poaching of multiple species in 2008 , we examined available poaching data from rhinos, tigers, and leopards from PoachingFacts and the Wildlife Protection Society of India (www.poachingfacts.com, www.wpsi-india.org). Similarly, we used data on total purchases of jewelry, gold, and diamonds in China (Hsu et al., 2014) to understand whether economic events in 2008 caused a general increase in investment in valuable raw materials.

\section{Empirical approach}

In an ideal experiment designed to measure the effect of legalization on black market production of a banned good, we would observe two identical black markets (that were isolated from one another), introduce a white market to the environment of one and compare illegal production across these "treatment" and "control" conditions. The 2008 sale, which was viewed by many as an actual experiment, approximates these conditions because the the global black market for ivory just before the sale can be considered a "control" for the same global black market just after the sale "treatment." So long as other important characteristics of the global black market vary smoothly across the moment of the sale, we can employ an event study design (Kothari and Warner, 2006) -identical to a regression discontinuity design (Lee and Lemieux, 2010) where time is the running variable - to identify the causal

effect of the sale. Under this approach, the effect of the sale is identified as any discontinuous response in the outcome that occurs in response to the sale. The goal of our analysis is to measure the sign and 
magnitude of this discontinuity.

\section{Econometric models}

For site $i$ in country $j$ in year $t$, the simplest panel model of poaching activity that we estimate is

$$
P I K E_{i j t}=\mu_{i}+\gamma_{t}+\epsilon_{i j t}
$$

where $\mu_{i}$ is a site fixed effect, $\gamma_{t}$ is a year effect, and $\epsilon_{i j t}$ is all remaining unexplained country and sitelevel variations, which we verify are homoscedastic and indistinguishable from a normally distributed random variable (see appendix). The site fixed effects account for all constant local factors, such as average elephant mortality, climate, socio-economic conditions, and levels of human-elephant conflict; in addition these site fixed effects also absorb all national level constant factors, such as institutional conditions, rates of corruption, and access to global markets. Further, these site fixed effects remove any bias in trends due to compositional changes in which sites report data in different years, which is important because our panel is unbalanced. The year effects capture all global changes in poaching that are common to all sites. If global black markets adjust abruptly to the legal sale of ivory, this effect will be measured by a change in $\gamma_{t}$ for years following the sale. Because temporary policies or changing economic conditions within a country may be correlated across sites or across periods, we assume that residuals $\epsilon_{i j t}$ might be correlated across sites within a county and over time, leading us to cluster our standard errors by country (Bertrand, Duflo, and Mullainathan, 2004).

Accounting for trends Because some factors that influence poaching, such as the affluence of potential ivory consumers or the level of organization in poaching syndicates, might change over the interval of observation, we employ a second model that additionally allows us to control for trends in these covariates. We thus additionally estimate

$$
P I K E_{i j t}=\mu_{i}+\theta t+\beta \times \text { post_event }_{t}+\epsilon_{i j t}
$$

where $\theta$ is a global trend and post_event is a dummy variable that is equal to one if the year is 2008 or later. Grouping observations based on whether they are before or after the sale is less flexible than the approach in Equation 5, but it is a standard approach that allows us to retain statistical power when we account for various trends (Wooldridge, 2010). For example, we can use this approach to simultaneously account for country or site specific linear trends $\left(\theta_{j}\right.$ or $\left.\theta_{i}\right)$. The average effect of the legal sale on PIKE (i.e. the size of the discontinuity between 2007 and 2008) is described by the coefficient $\beta$.

Accounting for trend breaks Trends in factors relevant to the global ivory market might change with time. In particular, the sale itself might alter market trends because the quantity of legal ivory circulating in Asian markets grows gradually as Chinese and Japanese governments gradually release

legal ivory into domestic markets. To account for this, we model both the change in level and trend of PIKE that occurs at the time of the sale using the "trend break" model

$$
P I K E_{i j t}=\mu_{i}+\theta_{(i j)} t+\left(\theta_{(i j)}^{\prime} t+\beta\right) \times \text { post_event }_{t}+\epsilon_{i j t}
$$


where $\theta^{\prime}$ is the change in the trend that occurs after the sale event. The total trend after the sale is $\theta+\theta^{\prime}$. Because pre- and post-sale trends might diverge across localities, especially because governments might respond differently to the sale, we also allow for both the pre-sale trend and the post-sale trend to differ either by country $j$ or by site $i$. Note that the version of Equation 7 using site-specific trend breaks is exceptionally flexible as it allows for trends in poaching conditions, which might be responding to highly localized labor market conditions or changes in local law enforcement, to vary independently before and after the sale across all sites.

Additional derivation and discussion of Equations 5-7 and their key assumptions are contained in the appendix.

\section{Timing of decisions related to the sale}

The identifying assumption of our research design is that the exact timing of the sale announcement was not anticipated before it occurred. If black market suppliers anticipated the announcement, they may have begun to alter their production activity prior to the sale. If this were true, it would likely cause us to underestimate any effect the sale might have had because pre-sale poaching would look more similar to post-sale poaching behavior.

Historical accounts of the decision to allow the 2008 sale suggest it would have been difficult to anticipate. The highly politicized and controversial nature of the sale to China, where black market activity was considered highly active, led to considerable debate and uncertainty as to whether a sale should take place and when it might occur. A CITES Secretariat mission to China in March 2008, after which investigators reported satisfaction with China's system of inspections and illegal ivory seizures, ultimately became the basis of the Secretariat's recommendation in July that the sale to China be approved and thus may have provided the earliest hints that CITES might allow the sale. However, given the uncertainty among stakeholders and decision makers involved in the sale, it seems unlikely that illegal ivory producers could have anticipated the July 2008 announcement earlier than 2008.

Table 1 supports this argument by documenting the timing of key events relevant to the sale. ${ }^{12}$ The 2008 approval of China as a trading partner was abrupt and unexpected; many non-profit organizations were fighting hard to prevent further sales of ivory, especially to China (The Economist, 2008; International Fund for Animal Welfare, 2006). For example, CITES rejected China's application to sell in 2007 when conditions were relatively similar, suggesting that prediction of the 2008 approval would have been challenging.

\footnotetext{
${ }^{12}$ The timeline also demonstrates how our results are inconsistent with two additional hypotheses that have been previously proposed to explain the recent rise in elephant poaching. The first suggests that the Chinese government set an artificially high price for resale of its purchased ivory in its domestic market (Christy, 2012; Levin, 2013), inducing additional poaching activity (Christy, 2012). However, China's high domestic price was unexpectedly revealed in 2009 (Christy, 2012), after the abrupt increase in PIKE occurred in 2008. A second hypothesis argues that CITES' refusal to lift the moratorium on future legal ivory sales was responsible for the increase in poaching (Stiles, 2012; Milliken et al., 2013). Specifically, observers have suggested that the combination of (i) a 2007 CITES commitment to disallow future sales of ivory for nine years (from the time of the upcoming sale) from Botswana, Namibia, Zimbabwe, and South Africa and (ii) CITES' 2010 denial of a legal ivory sale by Tanzania and Zambia signalled to markets that legal ivory sales were unlikely in the near future. The timings of these refusals do not match the observed 2008 change in PIKE.
} 
Table 1: A timeline of events related to the 2008 legal ivory sale

\section{Year Events}

1989 The Convention on International Trade in Endangered Species (CITES) bans international trade in African elephant ivory (international trade in Asian elephant ivory already banned) (Lemieux and Clarke, 2009).

1999 One-time sale of ivory from Botswana, Namibia, and Zimbabwe to Japan occurs (Bulte, Damania, and Kooten, 2007).

2002 CITES approves ivory stocks held by Botswana, South Africa, and Namibia for another one-time sale. However, the sale is not to occur "before May 2004", and is contingent on the verification of "prospective importing countries." At this time, Japan is the only country to have ever been approved as a trading partner for ivory since the 1990 ban (CITES Conference of the Parties, 2002).

2004 China establishes an ivory registration and licensing system and other mechanisms to meet CITES requirements, hoping to be declared a trading partner for ivory (International Fund for Animal Welfare, 2006).

2005 A CITES technical team visits China and declares the systems in place for registration and licensing to be "demonstrably effective" (CITES Standing Committee, 2005b).

However, the CITES Standing Committee declares that China's status as a "destination for illicit trade in ivory" makes it inappropriate to declare China a trading partner (CITES Standing Committee, 2005b).

2006 The CITES Standing Committee re-approves Japan as a trading partner, but also requests that any reasons for reviewing this decision be presented the following year (CITES Standing Committee, 2006).

The committee decides not to make any decision about China's status as a trading partner for the time being (CITES Standing Committee, 2006).

2007 CITES approves Zimbabwe's ivory stocks for a (thus-far unscheduled) upcoming one-time sale (CITES Standing Committee, 2007a).

CITES confirms that Japan shall remain a trading partner for the one-time sale (CITES Standing Committee, 2007b).

In a six to six vote, the CITES Standing Committee rejects China's request to be made a trading partner, declaring the topic will be further discussed in the next year (CITES Standing Committee, 2007c).

CITES declares a nine-year moratorium on further sales of legal ivory from the four countries participating in current one-time sale; the moratorium is to begin the year of the impending sale (CITES Standing Committee, 2007a).

2008 March: The CITES Secretariat undertakes a "final mission to China" and reports that "no irregularities" were found in Shanghai's stores of seized ivory or the city tourist area. (CITES Standing Committee, 2008a).

July: The CITES Standing Committee verifies ivory from Botswana, Namibia, South Africa, and Zimbabwe were of legal origin and are ready for sale (CITES Standing Committee, 2008a).

July: The committee also approves China as a trading partner that may participate in the sale (CITES Standing Committee, 2008a).

October/November: Ivory from African range states is auctioned off to China and Japan (CITES Standing Committee, 2009).

2009 Export of ivory from southern Africa occurs in February and March (CITES Standing Committee, 2009).

Final inspections of Chinese and Japanese shipments occur in March and April, respectively (CITES Standing Committee, 2009).

China announces domestic ivory price.(Christy, 2012)

2010 CITES rejects Tanzania's and Zambia's requests to allow one-time sales of their stockpiles of ivory (Stiles, 2012). 


\section{Results}

\section{Illegal primary production of ivory via poaching}

Figure 2A displays the distribution of PIKE each year across all sites after site-level averages are removed from the data, equal to $\gamma_{t}+\epsilon_{i j t}$ in Equation 5. Upward trends at the 95th centile are unchanged through the sale event, but the rest of the distribution shifts upward abruptly in 2008. A discontinuous change in poaching is clear with only this minimal amount of data processing.

\section{Main result}

Our main result is shown in Figure 2B, which displays year effects estimated from Equation 5 via OLS. ${ }^{13}$ Confidence intervals are for changes in mean site-level PIKE relative to 2007, the year just before the sale announcement. Average PIKE before 2008 was 0.34 and increased abruptly to 0.50 for the period after the sale, an increase of $0.16( \pm 0.026, \mathrm{p}<0.01)$. This average increase is partially attributable to a clear highly significant discontinuous increase of PIKE by $0.13( \pm 0.05, \mathrm{p}<0.05)$ in 2008, a $38 \%$ increase above pre-sale PIKE, and an increase in the annual trend of PIKE from 0.001 $( \pm 0.02)$ per year before the sale to $0.012( \pm 0.013)$ per year after the sale. This change in the trend is estimated using Equation 7 and is not itself significant. The abrupt 38\% increase in PIKE corresponds with roughly a $66 \%$ increase in poaching rates, since PIKE is a nonlinear combination of poaching rates and natural mortality. ${ }^{14}$

The persistence of elevated poaching rates after 2008 is notable and consistent with both supply and demand effects because ivory is a durable good. ${ }^{15}$ Once a legal stock of ivory is released into a market, it can continue to circulate and mask illegal supplies for decades. Similarly, if observing legal ivory alters demand by consumers, then the sale of legal stocks could continuously influence demand as a stream of potential consumers may be exposed to the legal ivory throughout its lifetime. In contrast, a temporary increase in the flow of legal ivory to markets would only competitively displace illegal flows temporarily. Although, notably, Chinese and Japanese governments were gradually selling off their legal stocks in domestic white markets in the years following 2008, so any temporary effects of competitive displacement would have been occurring continuously during this period.

We note that the abrupt and persistent increase in average site-level PIKE contrasts with the widely referenced temporary 2009 decrease in time series of globally aggregated PIKE, the ratio of total

\footnotetext{
${ }^{13}$ OLS is the best linear unbiased estimator under normally distributed homoscedastic residual variation (Wooldridge, 2010), a condition suggested by Figure 2A which we verify formally in the appendix.

${ }^{14}$ Since the PIKE index is the ratio of illegal to total (legal plus illegal) mortality, we must convert a change in the PIKE index to a change in the estimate rate of illegal killing. To ensure a consistent comparison, we estimate poaching rates based on pre-sale PIKE and legal mortality, then estimate how poaching rates must change to produce a $38 \%$ increase in PIKE. Pre-sale PIKE was 0.34 with average legal mortality in 2007 of 13.57 carcasses per site. Transforming the equation of PIKE, this implies predicted_illegal $2007=0.34 \times 13.57 /(1-0.34)=6.99$. Holding all values fixed but increasing PIKE by 0.13 , the size of the discontinuity, provides predicted_illegal $2008=(0.34+0.13) \times 13.57 /(1-0.34-0.13)=12.04$, a $72 \%$ increase. If instead we substitute the average legal mortality rate in 2008 of 13.09, then we obtain predicted_illegal $2008=$ 11.61 , a $66 \%$ increase. We adopt the latter approximation because it seems more conservative. In an alternative approach presented below, we model legal mortality directly in a Poisson regression and recover quantitatively similar results.

${ }^{15}$ Analogous temporary legal sales of nondurables, such as drugs, would not be expected to have persistent effects because they can no longer mask illegal supplies and likely exert less influence on black market demand after they are consumed and are no longer observable.
} 


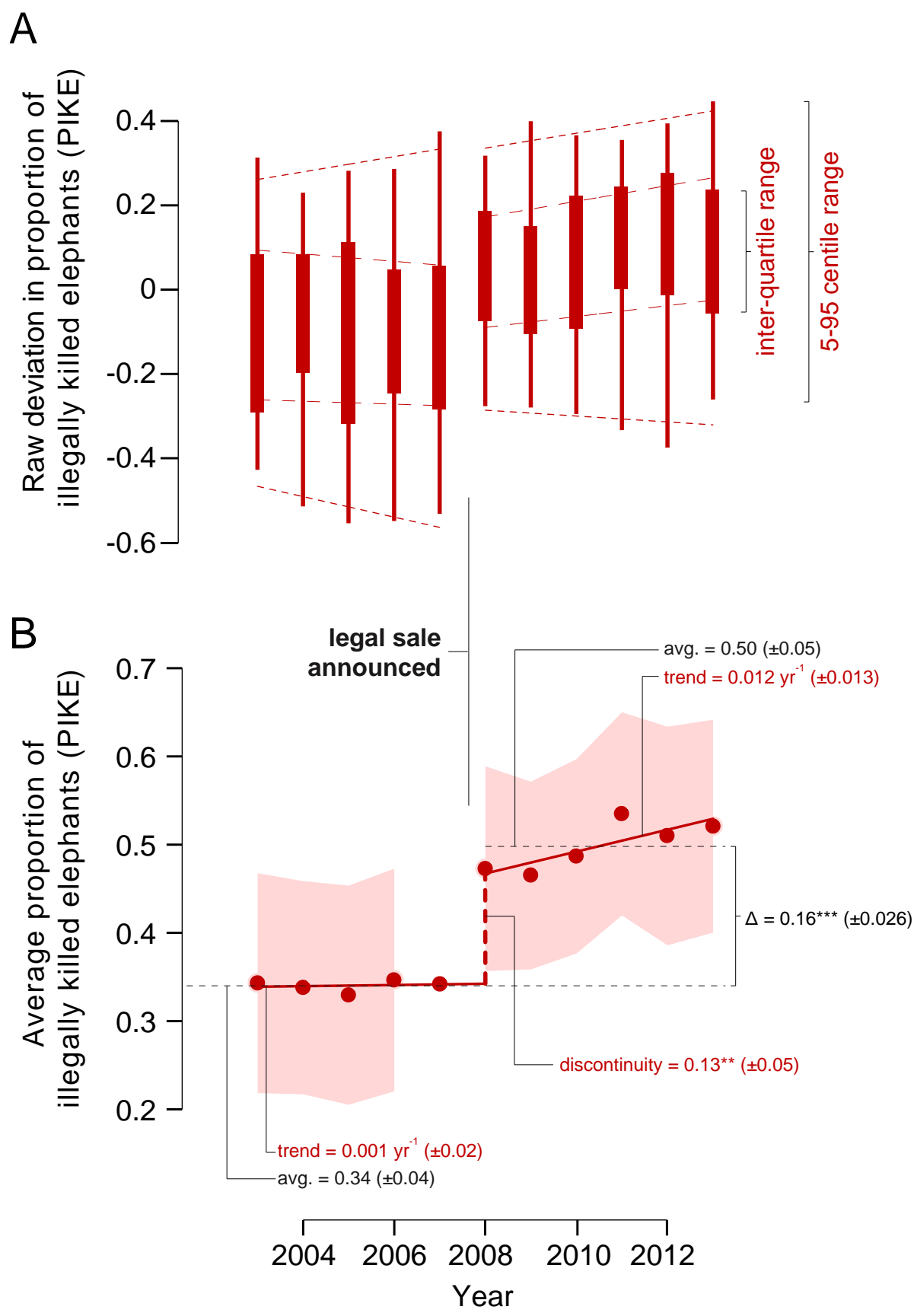

Figure 2: Effect of legal ivory sale on PIKE ( $\mathbf{N = 5 6 2 ) . ~ ( A ) ~ R a w ~ a n n u a l ~ d i s t r i b u t i o n ~ o f ~ t h e ~}$ fraction of dead elephants found to have been illegally killed (PIKE) after site-level fixed effects are removed from the data. Sample includes all reporting countries. Boxes are inter-quartile ranges and whiskers contain the inner $90 \%$ of observations. Long-dash lines are trend in 25 th and 75 th quantiles before and after the 2008 sale announcement. Short-dash lines are same, but 5th and 95th quantiles. (B) Annual average site-level PIKE, adjusted for all constant site-specific differences (fixed effects, as in B), estimated relative to average pre-sale PIKE in 2007 (i.e., 2007 is the reference category). 95\% confidence intervals (clustered by country) for pair-wise comparisons against average PIKE in 2007, immediately before the legal sale was announced in 2008. Dashed black lines mark average values before and after sale. Solid red lines mark trend break in PIKE before and after sale. Dashed red line is the estimated discontinuity in PIKE contemporaneous with the sale announcement the trend break model. All estimates report standard errors (clustered by country) in parentheses. 
illegally killed elephants to total legal mortality

$$
\text { Aggregate_PIKE } E_{t}=\frac{\sum_{i} \text { illegal_carcasses }_{i j t}}{\sum_{i}\left(\text { legal_mortality }_{i j t}+\text { illegal_carcasses }_{i j t}\right)}
$$

As shown in the appendix (Section E and Figure A10), this temporary decline is largely due to the distortion of the sum in the denominator by extraordinary $(>9 \sigma)$ natural elephant mortality due to drought in two Kenyan sites in 2009, events which would have far less influence in our panel approachalthough as described earlier, these two observations are dropped in our main analysis.

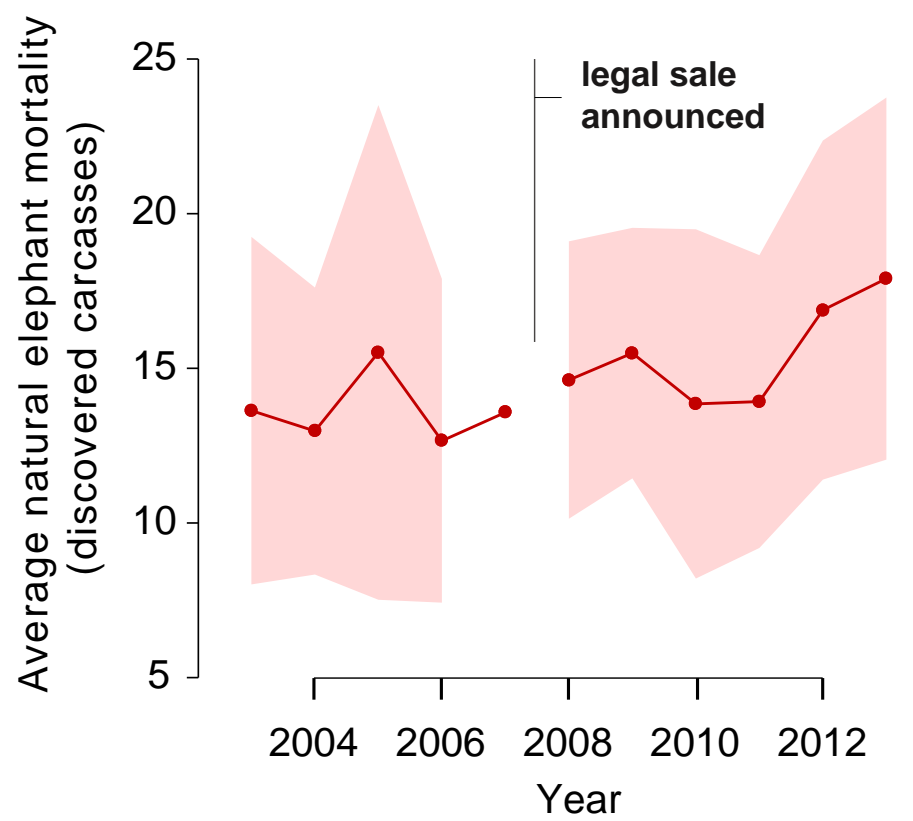

Figure 3: Effect of legal ivory sale on count of legal elephant carcasses. Same as Figure 2B, but for count of elephant carcasses that are discovered and determined to have died of natural causes or were killed legally. No changes in legal carcasses are statistically significant.

\section{Natural elephant mortality}

Because the PIKE measure uses the discovery of natural elephant mortality to account for variations in baseline elephant populations and the discovery rate of carcasses by field workers at MIKE sites, we check that the 2008 discontinuity in PIKE is not driven by an abrupt jump downward in natural mortality rates. To check that this, we apply Equation 5 to legal_mortality $i t$ exactly as it was applied to PIKE $E_{i t}$. The results are presented in Figure 3. There is no abrupt decline in legal mortality in 2008 and the difference between legal mortality rates before and after the sale are almost identical and are not statistically different. If anything, there is a small increase in legal mortality following the sale, which could slightly bias our main result towards zero by reducing post-sale PIKE. 


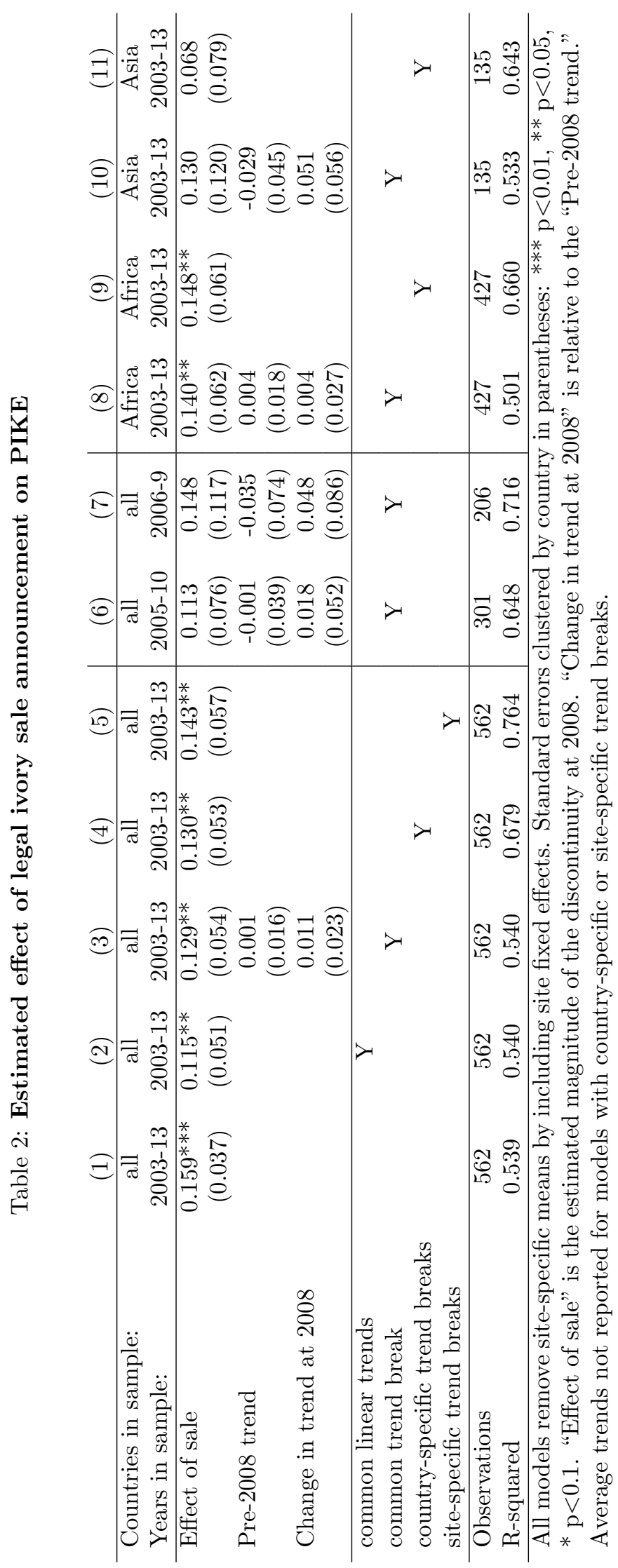




\section{Robustness to trend assumptions}

The estimated size and significance of the 2008 discontinuity in PIKE is robust to assumptions that there (1) is no trend, (2) is a common secular trend, (3) is a trend that breaks in 2008, (4) are common trend breaks within each country, (5) are unique trend breaks at each site. Column 1 of Table 2 presents regression estimates of Equation 6 when the trend is omitted, this is identical to the level effect shown in Figure 2B. Column 2 presents estimates when a constant global trend is included. Column 3 presents estimates from a model that assumes a global trend break as in Equation 7, this is identical to the discontinuous trend break shown in Figure 2B. Columns 4 and 5 present estimates when trend breaks are allowed to be country- and site-specific, respectively. Across these various models, the estimated size of the discontinuity varies across the narrow range of values $0.12-0.16$ and is statistically significant in all cases.

\section{Narrowing the window of analysis}

As an alternative to making assumptions about the structure of secular trends, we can check the robustness of our results by "zooming in" to the moment of the event, narrowing the window of years that we examine (Kothari and Warner, 2006). To implement this, we repeat estimation of Equation 7 only using data immediately before and after the sale. This approach reduces the influence of observations far from the discontinuity, thus preventing trends from biasing our point estimates. The primary tradeoff of this approach is that uncertainty increases because the size of the sample is reduced substantially. Columns 6 and 7 in Table 2 present estimates using \pm 2 and \pm 3 year windows around 2007, respectively. Consistent with our main finding, our point estimates remain essentially unchanged, although statistical uncertainty rises as expected. ${ }^{16}$ When the sample is restricted to 3 years before and after the announcement, the size of the estimated discontinuity in PIKE is 0.11, while when the sample is restricted to 2 years before and after, the discontinuity is 0.15 . These two estimates are very near and well within one standard error of the main estimate of 0.13 , suggesting our main estimate is unlikely to be biased by omitted trends.

\section{Regional and national subsamples}

Columns 8-11 in Table 2 present the estimated discontinuous increase in PIKE separately for Africa and Asia. The magnitude of effects in both regions are similar to our main estimate, although the effect is significant in Africa $(\mathrm{N}=427, \mathrm{p}<0.05)$ but not in Asia $(\mathrm{N}=135)$, perhaps because there is less data available. Focusing within Africa, we decompose the average effect across the continent into partial contributions from each country by interacting country-dummy variables with the post-sale indicator variable. Coefficients are displayed as colors in Figure 4. Notably, the average increase in PIKE is not driven by outliers but is pervasive across Sub-Saharan Africa and is individually significant in 9 separate countries. One out of 26 countries has a significant decline in poaching at the $5-10 \%$ level, an outcome likely to occur due to random sampling.

\footnotetext{
${ }^{16}$ Because the size of standard errors increases, these estimates are no longer statistically significant, however the purpose of this test was to check for bias in the point estimates, so significance is irrelevant.
} 


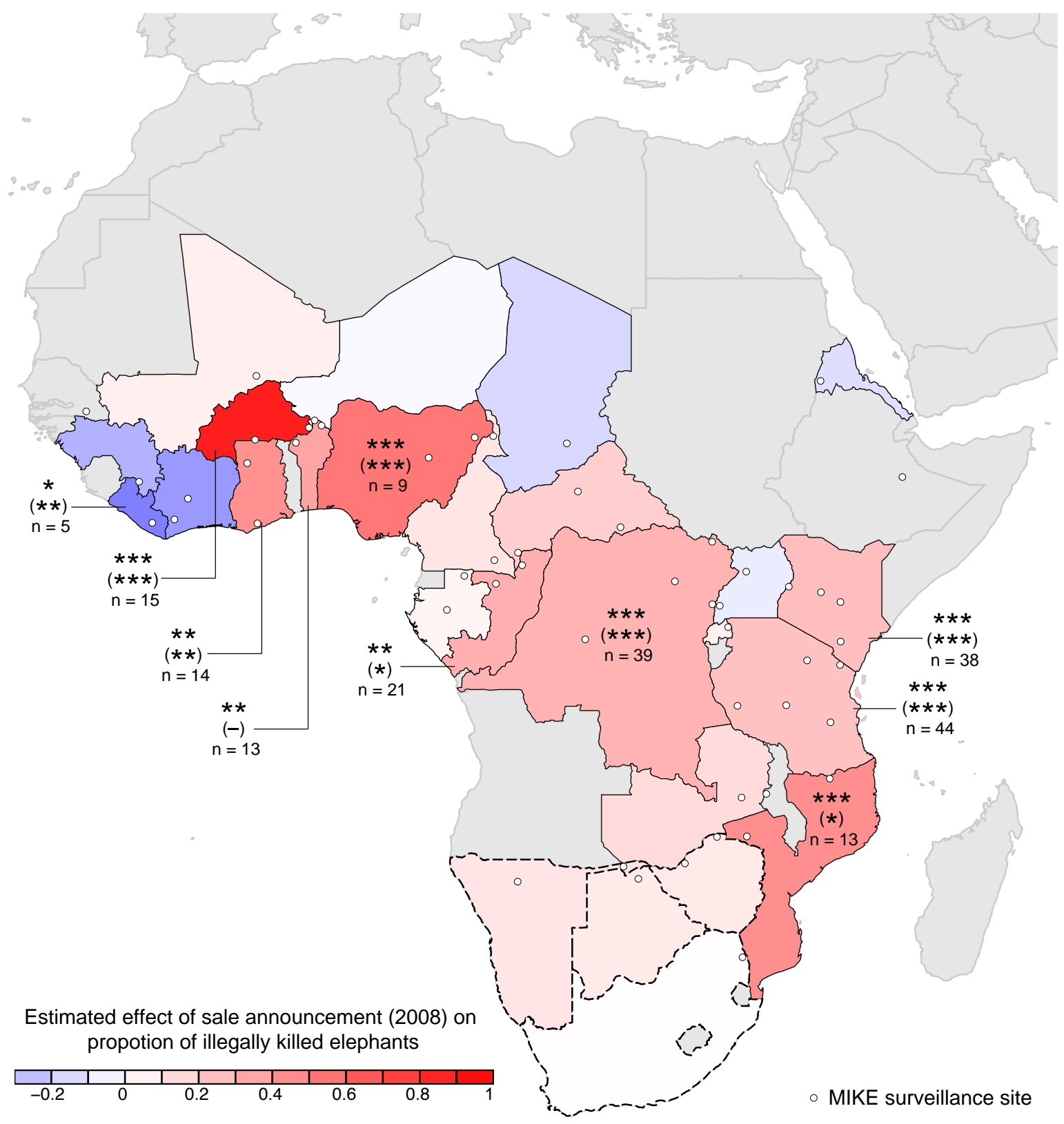

Figure 4: Estimated change in elephant poaching across African range states following the announcement of the legal ivory sale. The contribution of individual countries to the discontinuity shown in Figure 2B, with color indicating the average change in PIKE after the 2008 announcement across sites in each country. Stars indicate that the estimated effect in a single country is significant $\left({ }^{*} \mathrm{p}<0.1,{ }^{* *} \mathrm{p}<0.05,{ }^{* * *} \mathrm{p}<0.01\right)$ under standard assumptions, stars in parentheses indicate whether estimates are significant using bootstrapped s.e. ('-' indicates s.e. are inestimable). MIKE surveillance sites marked with circles. Countries with insufficient data are grey. Countries supplying legal ivory for the 2008 sale are outlined with dashed lines. 

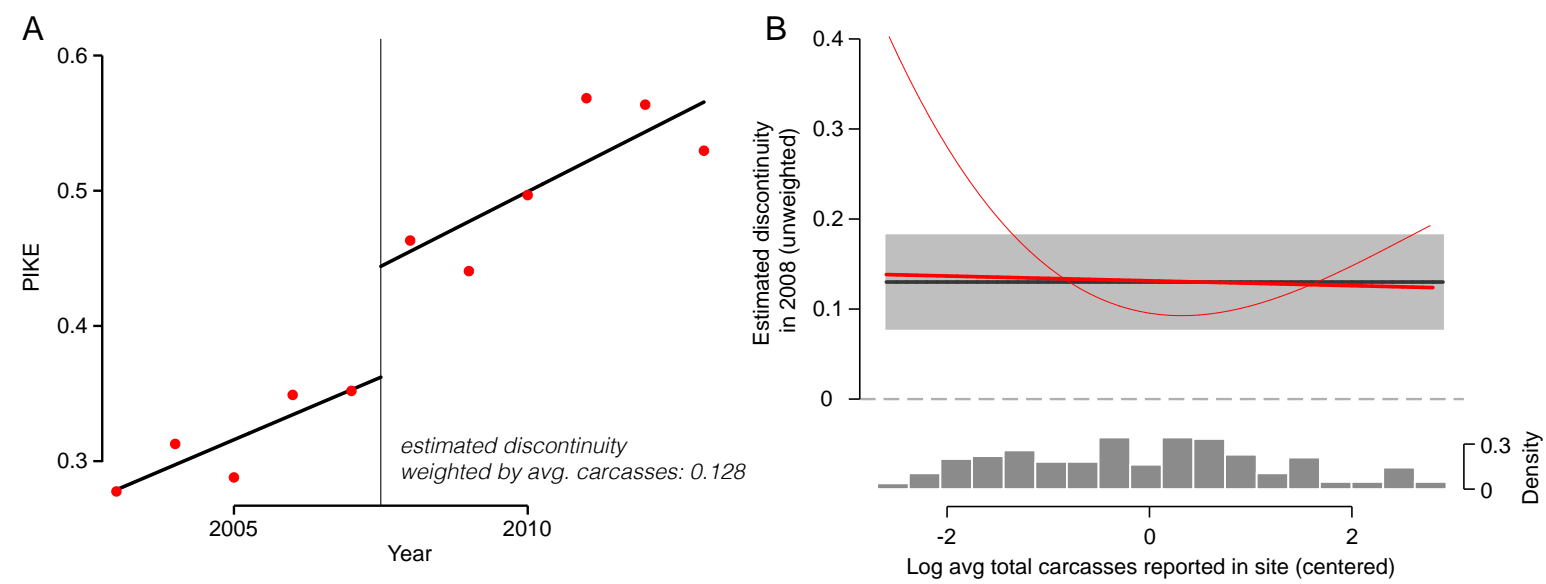

Figure 5: Robustness of discontinous behavior across sites of all different scales. (A) Estimated year effects and discontinuity (adjusted for site fixed effects) when observations are weighted by the average number of total carcasses (legal and illegal) discovered at each site (after outliers are dropped). (B) Estimated size of the 2008 discontinuity as a function of the scale of reporting in each site (unweighted). Solid black line is the benchmark estimate that pools all sites, gray band is $95 \%$ confidence interval. Thick red line interacts the post-2008 dummy with the log of average total carcasses reported at each site, histogram depicts density of observations. Thin red line interacts post-2008 dummy with cubic polynomial in the log of average total carcasses.

\section{Robustness to the scale of sites}

We verify that the overall average quantity of elephant mortality data collected at individual sites does not drive the magnitude of the estimated effect of the legal sale. A potential concern is that sites which report very few total carcasses overall, perhaps because they have small elephant populations or low levels of surveyor effort, will exhibit a large variance in PIKE because total carcasses are in the denominator of the PIKE measure. Thus large changes in PIKE could potentially be achieved at these sites even for small changes in illegal carcasses ${ }^{17}$. We verify that this issue does not drive our main result two different ways.

First, we re-estimate our main models weighting observations by the average number of total carcasses reported by each site during 2003-2013. This weighting scheme substantially reduces the influence of many sites that report few carcasses in general. As shown in Figure 5A, this approach substantially alters the pre-sale trend in PIKE, but causes essentially no change in the estimated magnitude of the 2008 discontinuity. The weighted discontinuity estimate of 0.128 is nearly identical to our benchmark estimate of 0.129 .

Second, we examine whether the magnitude of the 2008 discontinuity varies as a function of the number of total carcasses reported at each site. To do this, we adjust Equation 7 so that $\beta$ is allowed to be a function of the total carcasses reported at each site. We implement this by interacting the post2008 dummy with the log of average total carcasses reported per year in each site, while continuing to flexibly allow each country to have differing pre- and post-sale trends. The thick red line in Figure $5 \mathrm{~B}$ displays the predicted magnitude of the discontinuity estimated with this approach at sites that

\footnotetext{
${ }^{17}$ We thank Fiona Underwood, Quy-Toan Do, Andrei Levchenko, and Lin Ma for identifying this concern.
} 
Table 3: Estimated effect of legal ivory sale on PIKE when including 2002 data

\begin{tabular}{lccc}
\hline & $(1)$ & $(2)$ & $(3)$ \\
Years in sample & $2003-2013$ & $2002-2013$ & $2002-2013$ \\
\hline & & & \\
Effect of sale & $0.129^{* *}$ & $0.098^{*}$ & $0.107^{*}$ \\
& $(0.054)$ & $(0.049)$ & $(0.056)$ \\
Pre-2008 trend & 0.001 & 0.014 & 0.012 \\
& $(0.016)$ & $(0.015)$ & $(0.018)$ \\
Change in trend after 2008 & 0.011 & -0.002 & 0.001 \\
& $(0.023)$ & $(0.022)$ & $(0.026)$ \\
& & & \\
drop first obs. per site & & & Y \\
Observations & 562 & 581 & 504 \\
R-squared & 0.540 & 0.531 & 0.578 \\
\hline Dependent var
\end{tabular}

Dependent variable is PIKE. All models include site fixed effects and a common trend with a kink in 2008. Standard errors clustered by country in parentheses: ${ }^{* * *} \mathrm{p}<0.01,{ }^{* *} \mathrm{p}<0.05,{ }^{*} \mathrm{p}<0.1$. Sample is all countries. Column 1 includes our benchmark model and sample (same as column 3 in Table 2). Column 2 includes data from 2002, which is omitted from the benchmark model because of reporting irregularities probably related to the initial rollout of the surveillance program (see Appendix C). Column 3 is estimated using a restricted sample where the first observation in each site is dropped, an alternative approach to handling low quality data during surveillance rollout.

report different numbers of total carcasses, which is almost identical to the pooled estimate across all sites (black line). Allowing the response to the sale to be nonlinear in site scale, we interact $\beta$ with a cubic polynomial in log average total carcasses (thin red line in Figure 5B) and observe that throughout almost the entire support, the estimated effect is statistically indistinguishable from the pooled estimate. For the very smallest sites, the central estimate is larger, although not statistically different from the pooled estimate.

\section{Robustness to inclusion of 2002}

As described above and detailed in the appendix, data from 2002 - the first year that the surveillance system was deployed - is not comparable to other years in the sample, as the small number of sites surveyed that year were not surveyed during the entire twelve months of the year; this appears to have resulted in various irregularities in the data. These irregularities may also have been related to inexperience among new surveyors and management systems. For these reasons, we omitted 2002 from our main analysis. Nonetheless, we document that our main conclusions are robust to including 2002 in our sample. In Table 3 we display our main estimate (column 1) and the analogous estimate when 2002 is included in the sample (column 2). The estimated size of the effect of the sale becomes 
somewhat smaller at 0.098 ; this estimate is not significantly different from the result in our main analysis and remains significant at the $10 \%$ level. ${ }^{18}$

It is possible that irregularities in the 2002 data are due to newness of the surveillance network, causing sites to make errors or report elephant carcasses in nonstandard ways, perhaps due to inexperience. Should similar issues affect other sites that began reporting after 2002, it is possible that the first year of those records are biased in a similar way. Thus, we test whether our results are robust to eliminating the first year of data reported by each site, an alternative approach to simply dropping the year 2002 that treats time series from each site identically. Results from this alternative approach are shown in column 3 of Table 3; our main result remain significant and essentially unchanged.

\section{Robustness to including outliers}

As detailed in the appendix (Section B), three extreme outlying observations were dropped from our analysis because of exceptionally high legal mortality rates $(>9 \sigma)$. As mentioned earlier, these outliers substantially bias aggregate PIKE statistics used in prior analyses. We verify that inclusion of these outliers has no effect on our results (Appendix Figure A1B). Our panel approach is more robust to outliers because individual site-by-year observations are given less weight than when total carcass counts are summed to construct a globally aggregated time-series.

\section{Robustness to data file}

As described in the appendix (Section A), CITES provide two versions of the PIKE data via a CITES Github.com website (CITES MIKE, accessed 25-4-2015) and published CITES documents (CITES, $2012,2014)$ which differ in reported values for 18 site-year observations. Since the published data (CITES, 2014) were more recent and complete, we use these data in our main analysis. To ensure that our results are not sensitive to the differences in the data files, we also implement our analysis using the Github data augmented with data from CITES report SC65 Inf. 1 for 2012-2013 and site-years absent in the Github data (Appendix Figure A1C). Using the Github data, we estimate pre-sale PIKE was $0.326( \pm 0.04)$ compared to $0.340( \pm 0.04)$ using the report data. Post-sale values are $0.487( \pm 0.048)$ and $0.50( \pm 0.048)$, respectively. Our results do not change when we implement our analysis using the alternative CITES data file. Our results are also robust to use of the Github data file and inclusion of the outlier observations (Appendix Figure A1D).

\section{Outcome specification and Poisson regression}

Our main approach to estimating the effect of the legal sale is to use PIKE as our dependent variable, as in Equations 5-7. This approach follows the literature in ecology on the use of data from the field, where sampling may be strongly affected by natural factors and surveyor behavior, both of which are partially corrected for by normalizing illegal carcasses by the total count of carcasses found at each site (Burn, Underwood, and Blanc, 2011). Nonetheless, we verify that our result is robust to a different modeling approach, whereby we model the count of illegal carcasses discovered and do not assume

\footnotetext{
${ }^{18}$ Because 2002 is a large negative outlier, it causes the pre-2008 trend to be much steeper (see pre-2008 trend estimate in columns 1-2 of Table 3). This causes the fitted trend to lie above the data in 2007, thereby reducing the estimated size of the discontinuity.
} 
Table 4: Estimated effect of legal ivory sale on illegal elephant killing using alternative specifications

\begin{tabular}{|c|c|c|c|}
\hline & (1) & (2) & $(3)$ \\
\hline Effect of sale & $\begin{array}{c}0.377^{* *} \\
(0.181)\end{array}$ & $\begin{array}{c}0.422^{* * *} \\
(0.069)\end{array}$ & $\begin{array}{c}0.362^{* * *} \\
(0.070)\end{array}$ \\
\hline Pre-2008 trend & $\begin{array}{l}-0.005 \\
(0.056)\end{array}$ & $\begin{array}{c}0.028 \\
(0.018)\end{array}$ & $\begin{array}{l}0.033^{*} \\
(0.019)\end{array}$ \\
\hline Change in trend after 2008 & $\begin{array}{c}0.088 \\
(0.0)\end{array}$ & $\begin{array}{c}0.084^{* * *} \\
(0.021)\end{array}$ & $\begin{array}{c}0.084^{* * * *} \\
(0.022)\end{array}$ \\
\hline $\begin{array}{l}\text { Poisson regression } \\
\text { control for } \ln (\text { legal carcasses }+1) \\
\text { control } 5 \text { th-order polynomial in legal carcasses }\end{array}$ & $\mathrm{Y}$ & $\begin{array}{l}\mathrm{Y} \\
\mathrm{Y}\end{array}$ & $\begin{array}{l}\mathrm{Y} \\
\mathrm{Y}\end{array}$ \\
\hline Observations & 562 & 535 & 535 \\
\hline \multicolumn{4}{|c|}{$\begin{array}{l}\text { Dependent variable is } \ln (\text { illegal carcasses }+1) \text { in column } 1 \text { and count of illegal } \\
\text { carcasses in columns } 2-3 \text {. All coefficients are interpretable as log points. All } \\
\text { models include site fixed effects and a common trend with a kink in } 2008 \text {. } \\
\text { Columns } 1-2 \text { control for } \ln (\text { legal carcasses }+1) \text {. Columns } 2-3 \text { estimate a Poisson } \\
\text { fixed effects regression with a log link function. Column } 3 \text { controls for the } \\
\text { count of legal carcasses using a fifth-order polynomial in legal carcass count. } \\
\text { Standard errors clustered by country in parentheses: } * * * p<0.01, * * p<0.05 \text {, } \\
* \mathrm{p}<0.1 \text {. Sample is all countries, } 2003-2013 \text {. }\end{array}$} \\
\hline
\end{tabular}

the discovery rate for illegal carcasses is the same as that of legal carcasses, the implicit assumption adopted when using PIKE to correct for discovery rates.

First, we estimate the effect of the sale on $\ln ($ illegal_carcasses) at each site, controlling for the same variables as in Equation 7 but introducing an additional control variable for $\ln ($ legal_carcasses +1$)$ at each site:

$$
\ln (\text { illegal_carcasses }+1)_{i j t}=\phi \ln (\text { legal_carcasses }+1)_{i j t}+\mu_{i}+\theta t+\left(\theta^{\prime} t+\beta\right) \cdot \text { post_event }_{t}+\epsilon_{i j t} .
$$

The coefficient on legal carcasses $\phi$ will be equal to unity if the ratio of illegal carcasses to legal carcasses is fixed, although it is not assumed ex ante. The coefficient $\beta$ can be interpreted as the discontinuous change in the log of illegal carcasses that are discovered starting in 2008, controlling for the count of legal carcasses. Column 1 of Table 4 presents results using this approach. The estimated effect of the sale $\beta=0.377$ is large and statistically significant, indicating that poaching increased abruptly by roughly $46 \%$ in 2008 . This estimate is very near the $66 \%$ increase in poaching rates estimated using our benchmark approach.

In column 2 of Table 4, we estimate a model with conditional mean similar to Equation 8, however instead of using OLS we assume that the count of illegal carcasses follows a Poisson distribution and estimate the parameters describing the conditional mean via maximum likelihood. We continue to recover our main result, although the estimated effect is slightly larger, indicating a jump in poaching 
by roughly $50 \%$. Using this approach, the post-2008 change in the poaching trend by roughly $8 \% / \mathrm{yr}$ is highly statistically significant.

In column 3 of Table 4, we estimate a similar model to column 2 but instead of controlling for the $\log$ of legal carcasses +1 , we control for the count of legal carcasses using a fifth-order polynomial. This alternative approach allows us to flexibly account for the number of legal carcasses discovered without requiring that we add one to the count of legal carcasses, which is a standard albeit ad hoc solution to the issue that the log of zero is not well defined ${ }^{19}$ (in cases where no legal carcasses are discovered). This alternative approach recovers nearly identical estimates.

\section{Seizures of ivory contraband}

If a legal international sale of ivory increases illegal production of ivory (poaching), as our main result suggests, we should expect to also see a rise in illegal international trade of ivory (smuggling). Thus, to provide corroborating evidence that the legal sale of ivory affected the rate of illegal elephant killing, we examine whether the legal sale altered intercepted illegal ivory shipments during 1989 to 2011. Importantly, however, data on seizures is an imperfect proxy measure for actual illegal trade levels, which are unobserved, because seizure rates may be partially confounded by unobservable changes in surveillance effort by law enforcement agencies (Milliken et al., 2013). For this reason, we interpret all seizure-based results cautiously and provide them only as corroborating evidence of our main PIKE results.

An additional complicating factor when analyzing seizures of ivory contraband is the potential for a delay between the sale announcement and changes in seizure rates. Contraband seizures occur, almost universally, further down the supply chain than the point of primary production where an elephant is killed. Generally, poachers sell ivory to middlemen in the bush, who transport ivory to inland consolidation hubs where it is gathered for transport to major export centers, such as ports and international airports (Christy, 2015). ${ }^{20}$ In principle, seizure of the ivory may occur along any leg of this supply chain, although the bulk of seizures occur at major export centers far downstream from the primary producers. Thus, when testing for changes in seizures rates that might match the 2008 increase in poaching, it is critical that we consider the potential for a delay between increases in poaching and detection of increases in smuggling. In general, logistical constraints make it almost impossible for a surge in primary ivory supply to instantly increase illegal export volumes at major export hubs hundreds or thousands of miles away.

There is very limited information available on the time it takes for a representative unit of ivory to travel from the site of harvest to the point of seizure, although two pieces of isolated information provide some sense of the lag. First, a recent study using carbon dating of African elephant ivory from 14 seizures found a median lag time across samples generally ranging between 6 and 35 months; with median lag times averaging to 19 months across the 14 seizures (Cerling et al., 2016). Second, in

\footnotetext{
${ }^{19}$ Another proposed correction for this issue is to use the inverse hyperbolic sine function, which approximates the natural logarithm function but is defined near zero (Burbidge, Magee, and Robb, 1988). We prefer using a flexible fifth-order polynomial because it is simple and will closely approximate the inverse hyperbolic sine function or natural logarithm if those are the correct specifications. If these other forms are not correct, then a polynomial specification may recover the correct structure when these other forms are too constrained.

${ }^{20}$ Further, it is possible that the ivory is then transported, worked, and re-exported multiple times before it reaches a final consumer.
} 


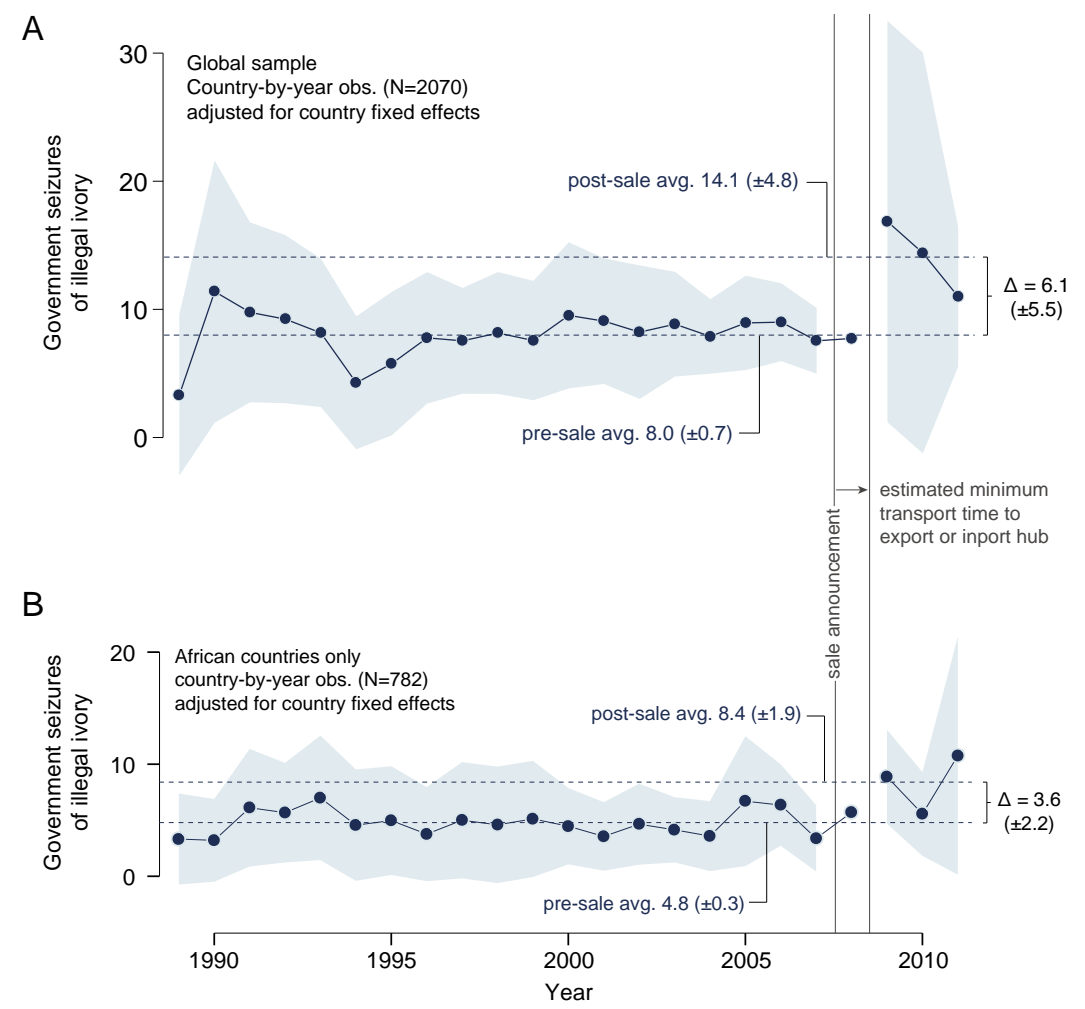

Figure 6: Effect of legal ivory sale on count of ivory contraband seizure events. (A) Same as Figure 2B in the main text, but for seizures globally. Comparisons are relative to 2008 because "postsale" years are coded to begin in 2009 based on to the estimated 5-9 month transit delay expected due to logistical constraints in the supply chain (see text). Dashed lines are average seizures per country before and after the sale. Standard errors in parentheses. (B) Same as A, but only for African countries.

an effort to track smugglers, (Christy, 2015) placed a GPS and transponder in a fake ivory tusk that he tracked after planting the tusk in Mboki, Central African Republic, a rural village known to be located along a smuggling route. The tusk was tracked for 53 days, during which it traveled 592 miles to Ed Daein, Sudan (where tracking ended because the tusk appeared to have been placed in storage), traveling an average pace of 11.2 miles per day. Hypothetically, if the tusk were to have traveled this speed along a direct path to the nearest coastal port (a path we have no evidence it took), then it would have reached its destination in roughly 4.5 months.

Because the legal sale announcement occurred in July 2008, it seems relatively implausible - based on these isolated observations - that even an immediate uptick in poaching could have triggered a major increase in seizures in less than five months. Thus in annual seizures data, one would not expect a rise in seizures before 2009, although longer delays might be plausible. Therefore, when we estimate Equations 5-6, in addition to altering them for country-by-year observations of ivory seizures we shift the defintion of "post-sale" observations to allow for a possible 2009 discontinuity instead of the 2008 discontinuity observed in the PIKE data. 


\section{ETIS count of seizure events}

Figures 6A displays results from applying Equation 5 to country-level data on seizure counts, i.e. the total number of seizure events by authorities, regardless of the quantity of ivory seized. Globally, average seizure rates rose roughly $6.1( \pm 5.5)$ seizures $\mathrm{yr}^{-1}$ per country in 2009, although the higher value and high variance of this estimate is largely driven by China, whose reported seizures rose abruptly by 475 seizures $\mathrm{yr}^{-1}$ on average. While this result seems to corroborate our central finding that the legal sale to China caused a rise in PIKE, it should be interpreted cautiously since the quality of China's seizure data is unclear. For example, in 2009 China redefined seizures to include "personal effects", including small ivory trinkets, that had previously been excluded from their ETIS reports (Milliken et al., 2013). We thus strongly suggest that the seizures count data is interpreted with caution.

Smuggled ivory may be seized in any country and much ivory is thought to recirculate across several borders after entering the global black market. Because we wish to focus on changes in primary production of new ivory harvested following the legal sale, we focus on attempted ivory export from countries where illegal ivory is harvested or through which new ivory is initially smuggled to global markets (Christy, 2015). In the period studied, most poaching for ivory occurred in African range states (Christy, 2012) - just in 2010-2012, the number of African elephants killed by poachers was twice the total population of wild Asian elephants (Wittemyer et al., 2014) - and most African countries are net exporters with limited domestic consumption, whereas domestic consumption, import, and re-export of old ivory is much more common in Asia (Christy, 2012). Thus, seizures in African countries, closer to sources of production, will likely be clearer indicators of illegal production. Restricting our sample to African countries, we apply Equation 5 and recover results shown in Figures 6B. Pre-sale average seizure rate rose from 4.8 to 8.4 seizures per year per country after 2009. Applying an analog to Equation 6, we estimate statistically significant and similarly sized increases of $3.4( \pm 1.4, \mathrm{p}<0.05)$ seizures per year. This point estimate suggests smuggling out of African countries may have increased abruptly by roughly $71 \%$, in close agreement with our main estimate that poaching rates increased roughly $66 \%$ at the time of the sale.

\section{Weight of seized ivory}

We also estimate how the total weight of ivory seized changed in 2009 , since these quantities are more difficult for authorities to manipulate, as highlighted by the Chinese example above. Globally, the total weight of seized ivory at the country level rose by roughly $312.4( \pm 136.6)$ kilograms per year in 2009. Pre-sale average seizure quantities rose from $274.6( \pm 36.0) \mathrm{kg} \mathrm{yr}^{-1}$ to $587.0( \pm 144.7) \mathrm{kg} \mathrm{yr}^{-1}$. Applying Equation 6, we estimate an average increase of $335.0( \pm 128.7, \mathrm{p}<0.1) \mathrm{kg} \mathrm{yr}^{-1}$. Figure 7 displays the estimated effect of the sale delivery on seized weight in the global and African subsample, for both raw ivory tusks and worked ivory (e.g. carvings). Roughly $90 \%$ of the increase in seized

ivory is raw ivory, with the vast bulk of it seized in Africa, consistent with the increase in seizures being related to the increase in primary production of illegal ivory and not just an increase in ivory smuggling activity generally. 

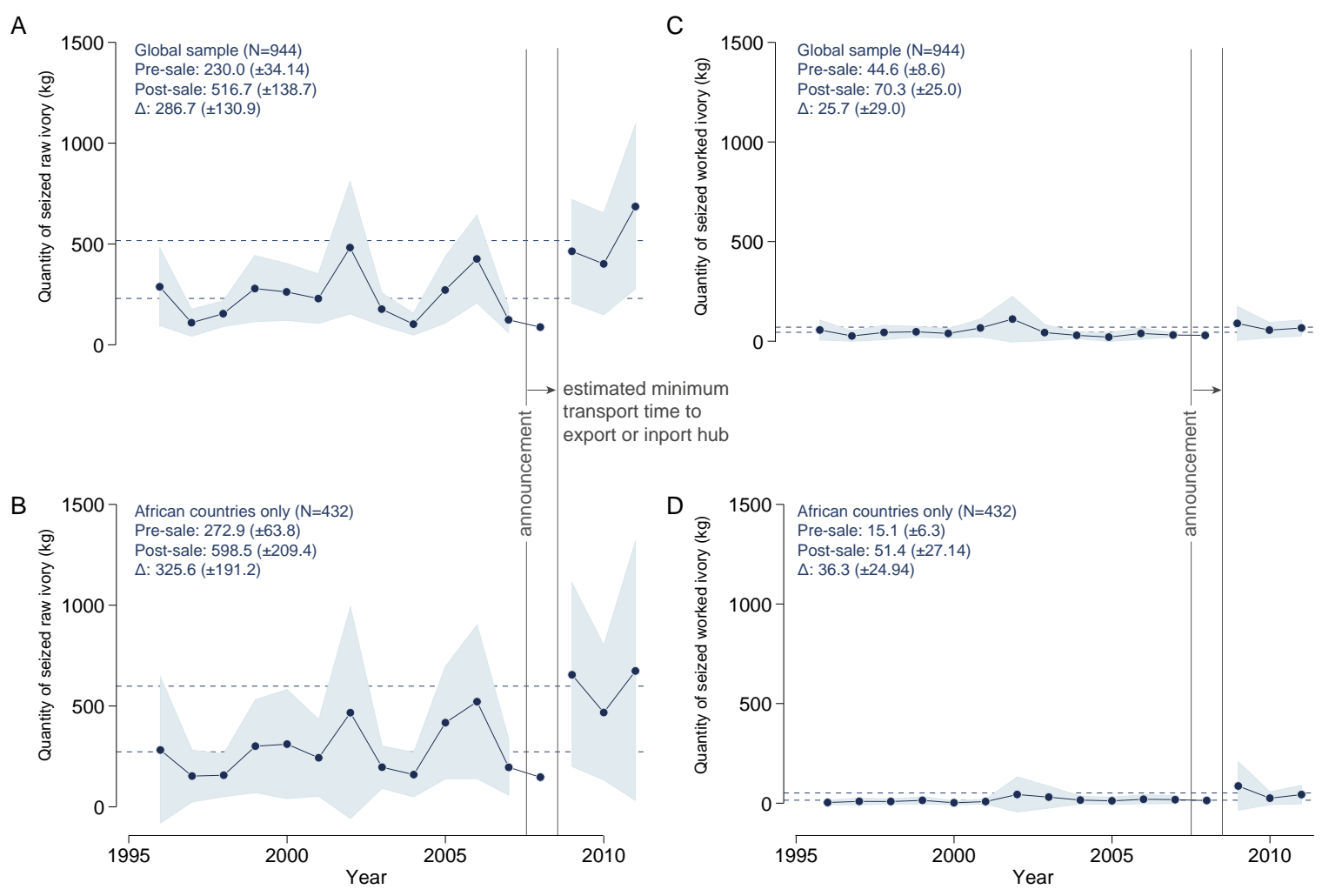

Figure 7: Effect of legal ivory sale on illegal ivory seizures by weight and whether raw or worked globally. (A) Same as Figure 6A, but for total mass of seized raw ivory. (B) Same as A, but only for African countries. (C) Same as A, but for worked ivory. (D) Same as B, but for worked ivory.

\section{Alternative theories}

Our event study research design permits causal inference if other factors known to affect PIKE are smooth across the moment of the event - i.e. that they do not exhibit discontinuities similar to Figure 2B. While it is impossible to test this assumption for the universe of potential confounders, we examine several key variables that might indicate possible violations of this assumption.

\section{Financial crisis in 2008}

The 2008 financial crisis is perhaps the most important possible confounding event for two reasons. First, it is possible that ivory was viewed as a safe investment in China at a time when financial markets were unpredictable, causing demand to increase for reasons other than the legalization event. Second, it may have lowered the opportunity cost of potential poachers, increasing their willing to supply illegal ivory to global black markets for reasons unrelated to the legal sale.

Ivory as an investment It has been widely suggested by the media and researchers that Chinese demand for illegal ivory should rise during financial crises, similar to demand for gold and other precious 

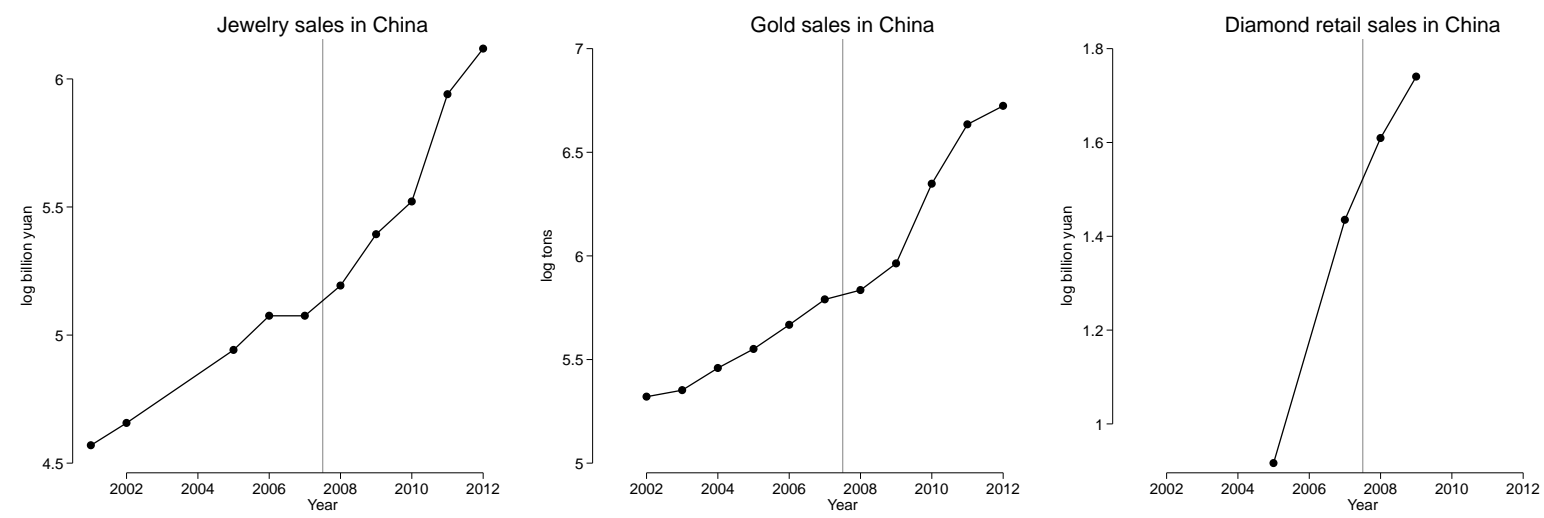

Figure 8: Total purchases of precious materials other than ivory in China during the period of the legal ivory sale. Vertical grey lines indicate the 2008 legal ivory sale. Data from Hsu et al. (2014).
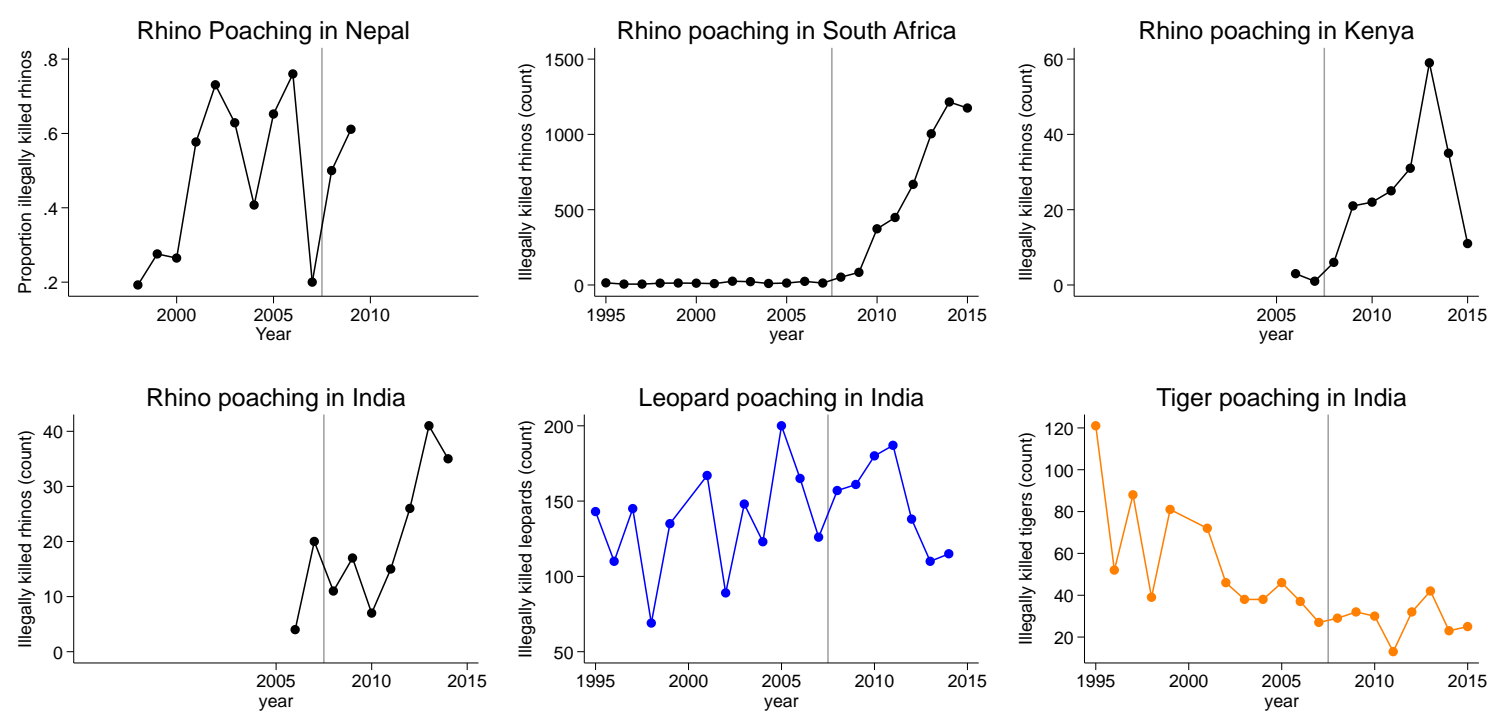

Figure 9: Available poaching data for large animals other than elephants from various sources. Vertical grey lines indicate the 2008 legal ivory sale. Only rhinoceros poaching in Nepal is normalized by total mortality (analogous to PIKE), all other data are simple counts of illegal carcasses. 
materials that retain their value, since it is a safe investment relative to other financial instruments. Thus, if such abrupt changes in demand for investments in precious materials was the cause for the 2008 uptick in poaching we observe, then we expect to see similar changes in Chinese demand for other products with this property. We obtain data on total jewelry sales, total gold sales, and total diamond retail sales in China during this period (Hsu et al., 2014) and plot these data in Figure 8. We find no analogous discontinuous behavior in 2008 for purchases of these three other precious materials, rather, there appears to be a slowing of sales for jewelry and gold between 2006-2009. This suggests that an increase in demand for ivory as an investment seems unlikely to explain the 2008 discontinuity in poaching.

Labor supply of poachers The labor market for poachers in remote regions of Africa and Asia is largely decoupled from global financial markets as non-poaching employment opportunities for these low-skilled workers tend to be in sustenance agriculture, other primary production for local consumption, or security related work (e.g. soldiers or law enforcement). Nonetheless, it is possible that general slowing of economic growth could induce some marginal workers to participate in elephant poaching, lowering the cost of supply and increasing overall production. We cannot observe these labor markets directly, however if this dynamic were responsible for the 2008 uptick in poaching, we would also expect it to cause an increase in the poaching of other large animals that provide similar economic payoffs as poaching elephants ${ }^{21}$. Unfortunately, the elephant poaching data we analyze is unique in its scope and systematic collection, so there is no comparable data set for other large animal species. Nonetheless, we are able to obtain times series ${ }^{22}$ for poaching of rhinoceros in Nepal, South Africa, Kenya and India, leopard in India, and tiger in India, which we plot in Figure 9. Only the data from Nepal records both illegal and legal carcasses, allowing us to compute a PIKE-like measure for rhinoceros; for the other data we only observe total illegal carcasses, so it is not perfectly comparable to our analysis of PIKE. Despite these limitations, we note there is no comparable 2008 discontinuity in poaching for any of these time series. The well-known recent acceleration of rhinoceros poaching is clearly visible, however rapid increases did not begin until 2009 in Kenya, 2010 in South Africa, and 2012 in India. Leopard poaching in India and rhinoceros poaching in Nepal show no clear trend nor discontinuity, and tiger poaching in India declined smoothly over this period. Taken together, these data do not suggest that the 2008 financial crisis triggered widespread global poaching of large animals by lowering the value of non-poaching employment. The discontinuous 2008 jump in poaching appears to be specific to elephants.

\section{Other factors}

The general rise in elephant poaching rates during the last decade have been a topic of vigorous public debate, with many researchers, journalists and policy-makers - unaware of the 2008 discontinuity we identify here - suggesting various causes, such as economic growth in consumer countries and elephant range states, the spread Chinese workers and their associated networks throughout range states, changing trade networks and relations between consumer countries and range states, and trends in political

\footnotetext{
${ }^{21}$ We thank Joseph Shapiro for suggesting this test.

${ }^{22}$ Tiger poaching in India is made publicly available by the Wildlife Protection Society of India (www.wpsi-india.org). All other poaching data is aggregated from various sources and made public by PoachingFacts (www.poachingfacts.com).
} 


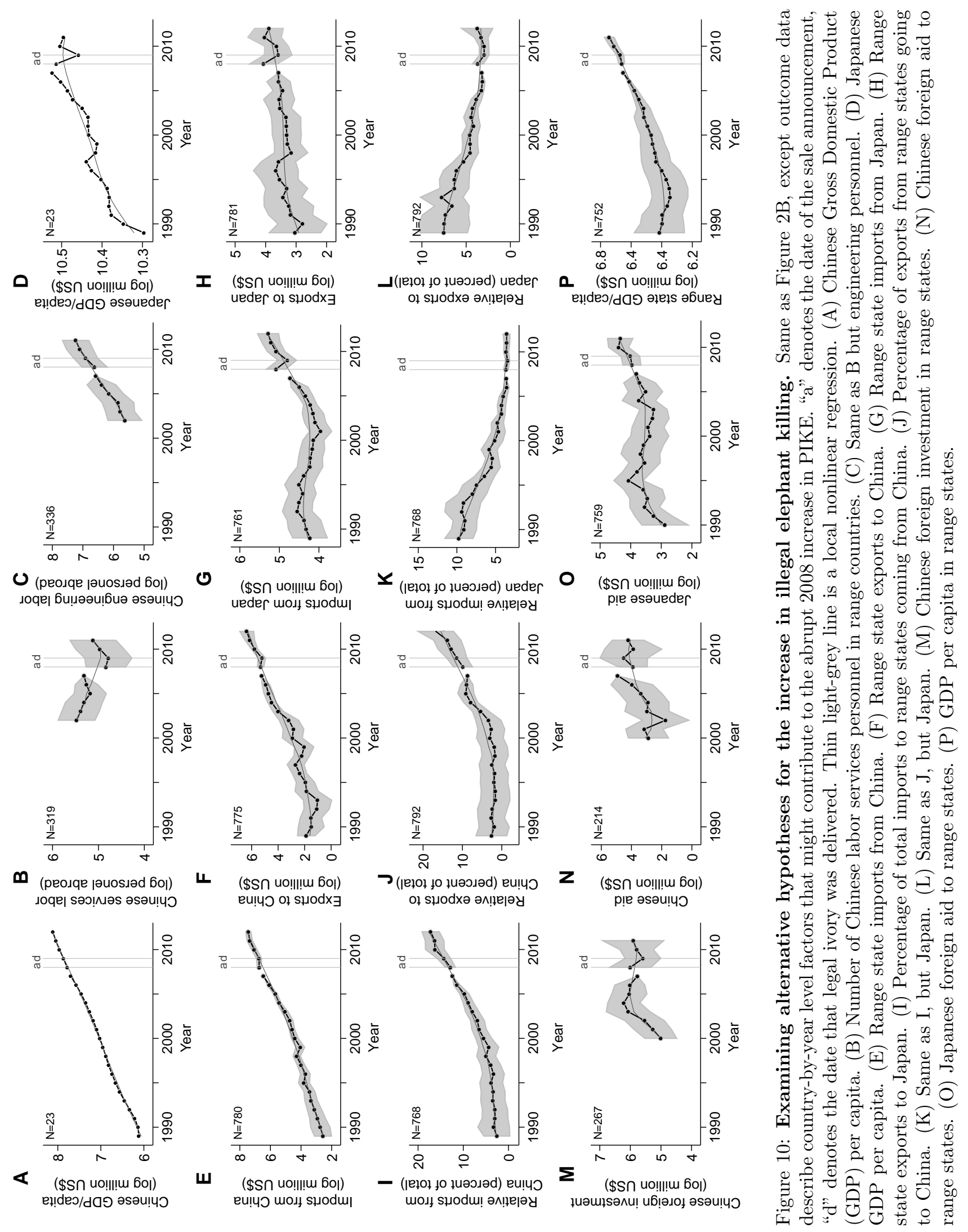


influence or corruption that are facilitated by foreign aid and investment from consumer countries into range states (Stiles, 2004; Khanna and Harford, 1996; Stiles, 2012; Milliken et al., 2013; Duanduan, 2013). To consider whether these mechanisms might be responsible for the observed 2008 discontinuity in poaching, we analyze sixteen covariates that are closely linked to these commonly proposed drivers of elephant poaching. Applying Equation 5 but replacing PIKE with these covariates, we examine Chinese affluence using per capita Gross Domestic Product (GDP), and we examine Chinese influence in elephant range states using trade measures (imports, exports, relative imports, relative exports), measures of China's financial influence in African elephant range states (foreign direct investment, foreign aid), and measures of China's physical presence in range states (service and engineering personnel) in Figure 10 (panels A-C, E, F, I, J, M, N). In addition, we repeat this analysis for Japanese GDP per capita, aid and trade data (Figure $10 \mathrm{G}, \mathrm{H}, \mathrm{K}, \mathrm{L}, \mathrm{O}$ ). We also examine GDP per capita of range states reporting PIKE since labor market conditions influence the opportunity cost of poaching (Figure 10P).

None of the resulting covariates show the abrupt and persistent level increase in 2008 that is visible for the PIKE data (Figure 2A). Chinese services labor exhibits the only discontinuous level-shift in 2008 (Figure 2B), however the change is a decline in Chinese presence, opposite the sign one would expect if this change explained the abrupt increase in PIKE. The same is true of Chinese aid and Japanese GDP. Imports to and from Japan rose idiosyncratically in 2008; however, unlike PIKE, both measures return to their trend in 2009.

We also analyze covariates using Equation 6; unlike with the PIKE data, which accommodate only linear trends with a break, we are able to fit the covariates data with models accounting for a) linear common trends, b) quadratic common trends, c) cubic common trends, or d) linear countryspecific trends. These analyses provide several instances which suggest a small, statistically significant, discontinuous increase in 2008 for the covariate analyzed. Based on these instances, the covariates can be placed in three categories:

1. Covariates for which the models accounting for country-specific linear trends indicate a statistically significant change in 2008 , but the models accounting for polynomial trends do not:

- Elephant range state imports from China (E): 2008 effect $=0.449, \mathrm{p}<0.01, \mathrm{n}=780$.

- Percent of elephant range state imports from China (I): 2008 effect $=0.036, \mathrm{p}<0.01, \mathrm{n}=768$.

- Percent of elephant range state exports to China (J): 2008 effect $=0.043, \mathrm{p}<0.05, \mathrm{n}=792$.

- Percent of elephant range state imports from Japan (K): 2008 effect $=0.017, \mathrm{p}<0.01, \mathrm{n}=768$.

- Percent of elephant range state exports to Japan (L): 2008 effect $=0.012, \mathrm{p}<0.05, \mathrm{n}=792$.

- Chinese direct \& other investment in range states (M): 2008 effect $=-0.617, \mathrm{p}<0.10, \mathrm{n}=267$.

2. Conversely, covariates in which only the models accounting for polynomial common trends indicate a significant change in 2008 :

- Number of Chinese personnel in range states for labor services (Panel B): 2008 effect = $-0.486, \mathrm{p}<0.10, \mathrm{n}=319$.

- Elephant range state exports to Japan (Panel H): 2008 effect $=0.433, \mathrm{p}<0.05, \mathrm{n}=781$. 
3. Covariates for which the linear and polynomial models suggest a statistically significant change in 2008:

- Elephant range state imports from Japan (Panel G): 2008 effect $=0.829, \mathrm{p}<0.01$ for linear models; effect $=0.499, \mathrm{p}<0.01$ for polynomial models; $\mathrm{n}=761$ );

- Japanese aid to elephant range states (Panel O): effect $=0.446, \mathrm{p}<0.05$ for linear models; 2008 effect $=0.560, \mathrm{p}<0.10$ for polynomial models; $\mathrm{n}=759$.

For many of the covariates in category 1, Figure 10 indicates that the underlying trend is likely to be nonlinear, suggesting the linear models fit are inappropriate. While R-squared and AIC measures suggest that country-specific linear trends models outperform polynomial models for all covariates, these improvements are likely a consequence of the large increase in predictors. Figure 10 does indicate a reasonably linear trend for imports from China (Panel E), but the discontinuity appears to be driven by a single point (2008), after which the data returns to trend.

In category 2, the number of Chinese personnel in range states for labor services (Panel B) does indicate a sharp discontinuity in 2008 - but as mentioned above the change is a decrease, contradicting the prevailing hypothesis about how the presence of Chinese citizens in range states affects the ivory trade. The other category 2 covariate, exports to Japan from range states, appears to show an anomalous increase in 2008 before returning to trend. This fails to reflect the permanent increase we found in PIKE.

In the third category, range state imports from Japan (Panel G) present a case similar to that of exports to Japan (Panel H), and appear to be driven by an anomalous increase in 2008. Japanese aid (Panel O) shows no obvious discontinuity at 2008, and the apparent discontinuity may be driven by anomalously high aid provided to range states in 2010 .

In sum, we fail to find evidence of a correctly signed and persistent discontinuous change in covariates that seems likely to explain the striking discontinuity in poaching. Further, while it is likely that increasing incomes in Asia might contribute to demand in the background, these incomes were rising continuously well in advance of the 2008 sale when there was no visible trend in poaching.

\section{Conclusions}

We examine a unique context where the technology of primary production allows us to observe illegal primary production before and after an experimental legal sale. We find that a singular legal ivory sale corresponds with an abrupt, significant, permanent, robust, and geographically widespread increase in the production of illegal ivory through elephant poaching, with a corresponding 2009 increase in seizures of raw ivory contraband leaving African countries. The sudden 2008 increase in poaching does not correspond with any abrupt and systemic change in China's or Japan's affluence or influence in elephant range states, as measured by numerous covariates.

Our results are most consistent with the theory that the legal sale of ivory triggered an increase in black market ivory production by increasing consumer demand and/or reducing the cost of supplying black market ivory, and these effects dominated any competitive displacement that occurred. In markets where supply and demand interact directly with legalization, price data are relatively uninfor- 
mative as to the effects of legalization. The data indicate illegal ivory suppliers anticipate opportunities to sell and/or smuggle illegal ivory, consistent with qualitative reports (Lemieux and Clarke, 2009).

Our findings demonstrate that partial legalization of a banned good can increase illegal production of the good because the existence of white markets may influence the nature of black markets. However, the exact relationship between legalization and illegal production documented here is not universal. To predict a specific market's response to legalization, we need supply and demand functions for legal and illegal versions of a good, as well as their sensitivity to legalization itself. Our findings are likely to extend to markets structurally similar to ivory markets, such as those for products from other slowgrowing, slow-breeding, or low-population density species like rhinoceroses and tigers. These species are difficult or impossible to produce in large quantities at low cost (Martin et al., 2012), limiting the ability of legal supplies to displace illegal supplies. In contrast, crocodiles have been reared at low cost (Hutton and Webb, 2002), allowing legal pelts to competitively displace illegal supply.

The insight that legalization does not always reduce black market activity may extend beyond the wildlife trade. For example, populations often consider relaxing bans on trade in drugs (Inciardi and McBRIDE, 1989), prostitution (Sullivan, 2007), weapons (Koper and Roth, 2002), and human organs (Goodwin, 2006) with a focus on the potential competitive displacement of illegal production. Our results demonstrate that supply and/or demand in these black markets are likely to respond directly to partial legalization, exerting some upward pressure on illegal production. The total effect of partial legalization on illegal production is determined by whether legal production displaces more production of illegal goods than it induces.

\section{References}

Abbott, Brant and G. Cornelis van Kooten. 2010. "Can domestication of wildlife lead to conservation? The economics of tiger farming in China." In AAEA, CAES 83 WAEA Joint Annual Meeting. 33 pp.

All China Data Center. 2013. "Chinese Statistical Yearbook." URL http://chinadataonline.org/ member/yearbooknew/yearbook/Ayblist . aspx?code=2014217185257mmt2.

Angrist, Joshua D. and Jorn-Steffen Pischke. 2008. Mostly Harmless Econometrics: An Empiricist's Companion. Princeton University Press.

Bamberger, Michael, Jim Rugh, and Linda Mabry. 2011. RealWorld evaluation: Working under budget, time, data, and political constraints. Sage publications.

Barbier, Edward B, Joanne C Burgess, Timothy M Swanson, and David W Pearce. 2009. Elephants, economics and ivory, vol. 3. Earthscan.

Barrett, Scott. 1994. "Self-enforcing international environmental agreements." Oxford Economic Papers :878-894.

Becker, Gary, Kevin Murphy, and Michael Grossman. 2006. "The market for illegal goods: the case of drugs." Journal of Political Economy 114 (1):38-60.

Becker, Gary S. 1968. "Crime and Punishment: An Economic Approach." The Journal of Political Economy 76 (2):169-217.

Bergstrom, Ted. 1990. "Puzzles: On the Economics of Crime and Confiscation." The Journal of Economic Perspectives :171-178.

Bertrand, Marianne, Esther Duflo, and Sendhil Mullainathan. 2004. "How Much Should We Trust Differences-In-Differences Estimates?*." The Quarterly journal of economics 119 (1):249-275. 
Biggs, Duan, Franck Courchamp, Rowan Martin, and Hugh P Possingham. 2013. "Legal Trade of Africa s Rhino Horns." Science 339 (March):1038-1039.

Bulte, Erwin, Richard Damania, and G. Kooten. 2007. "The Effects of One-Off Ivory Sales on Elephant Mortality." Journal of Wildlife Management 71 (2):613-618.

Burbidge, John B, Lonnie Magee, and A Leslie Robb. 1988. "Alternative transformations to handle extreme values of the dependent variable." Journal of the American Statistical Association 83 (401):123-127.

Burgess, Robin, Matthew Hansen, Benjamin A Olken, Peter Potapov, Stefanie Sieber et al. 2012. "The Political Economy of Deforestation in the Tropics." The Quarterly Journal of Economics 127 (4):1707-1754.

Burn, Robert, Fiona Underwood, and Julian Blanc. 2011. "Global trends and factors associated with the illegal killing of elephants: A hierarchical bayesian analysis of carcass encounter data." PloS one 6 (9):e24165.

CCTV.com. 2011. "Market of an Art Object- Ivory Sculpture." URL http://tv.cntv.cn/video/ c10330/7e7b5d36d2ba4817a6994b80c5636153.

Cerling, Thure, Janet Barnette, Lesley Chesson, Iain Douglas-Hamilton, Kathleen Gobush, Kevin Uno, Samuel Wasster, and Xiaomei Xu. 2016. "Radiocarbon dating of seized ivory confirms rapid decline in African elephant populations and provides insight into illegal trade."

China Statistics Press. 2006. "China Trade and External Economic Statistical Yearbook." Tech. rep.

. 2009. "China Trade and External Economic Statistical Yearbook." Tech. rep.

—. 2012a. "China Trade and External Economic Statisticaly Yearbook." Tech. rep.

—. 2012b. "Chinese Statistical Yearbook." Tech. rep.

Christy, Brian. 2012. "Ivory worship." National Geographic .

- 2015. "How Killing Elephants Finances Terror in Africa." National Geographic .

CITES. 2002a. "Illegal Hunting of Elephants." Tech. Rep. May. URL http://www.cites.org/eng/ cop/12/doc/E12-34-2.pdf.

- 2002b. "Statement of the Delegation of India regarding proposals for the reopening of international trade in ivory from the African elephant (Loxodonta africana)." Tech. Rep. November, CITES, Santiago, Chile. URL http://www.cites.org/sites/default/files/common/cop/12/ ESF12i-41.PDF.

2012. "Supplementary Information on Document SC62 Doc. 46.1." Tech. rep., Convention on International Trade in Endangered Species of Wild Fauna and Flora. URL http://cites.org/ eng/com/sc/62/Inf/E62i-01.pdf.

—. 2014. "Supplementary Information on Document SC65 Doc. 42.1." Tech. rep.

CITES Conference of the Parties. 2002. "Amendments to Appendices I and II of the Convention." Tech. Rep. November, Santiago, Chile. URL http://www.cites.org/sites/default/files/eng/ cop/12/Adopted_Amendments.pdf.

CITES MIKE. accessed 25-4-2015. "PIKE 2013." URL https://github.com/citesmike/mike_R_ analyses.

CITES Standing Committee. 2005a. "Control of trade in African elephant ivory." Tech. rep., CITES Standing Committee. URL http://www.cites.org/eng/com/sc/53/E53-20-1.pdf.

- 2005b. "Control of Trade in African Elephant Ivory." Tech. rep. URL http://www.cites . org/sites/default/files/eng/com/sc/53/E53-20-1.pdf.

. 2006. "Summary Record." Tech. rep., Geneva. URL http://www . cites.org/sites/default/ files/eng/com/sc/54/E54-SumRec.pdf. 
2007a. "Amendments to Appendices I and II of the Convention." Tech. rep., CITES Conference of the Parties, UNEP, Geneva. URL http://www.cites.org/sites/default/files/eng/notif/ 2007/E022.pdf.

2007b. "Control of trade in African elephant ivory." Tech. rep., CITES Standing Committee. URL http://www. cites .org/eng/com/sc/55/E55-10-1.pdf.

- 2007c. "Summary Record." Tech. rep., CITES Standing Committee. URL http://www . cites.org/eng/com/sc/55/E55-SumRec.pdf.

—. 2008a. "Control of trade in elephant ivory." Tech. Rep. June 2007, CITES Standing Committee. URL http://www.cites.org/eng/prog/mike/reg_meet/aem1/EN-E57-33-2.pdf.

- 2008b. "Summary Record." Tech. rep., CITES Standing Committee. URL http://www . cites.org/eng/com/sc/57/E57-SumRec.pdf.

. 2009. "Report on the one-off ivory sale in Southern African Countries." Tech. rep., CITES Standing Committee. URL http://www.cites.org/eng/com/sc/58/E58-36-3.pdf.

. 2012. "Elephant conservation, illegal killing and ivory trade." Tech. rep., CITES Standing Committee. URL http://www. cites.org/eng/com/sc/62/E62-46-01.pdf.

Costello, Christopher, Steven D Gaines, and John Lynham. 2008. "Can catch shares prevent fisheries collapse?" Science 321 (5896):1678-1681.

Duanduan, Yuan. 2013. "The Blood Ivory Behind the Largest Ivory Smuggling Cases in China." Southern Weekend URL http://newsroom.wildlifedirect.org/2013/12/03/ the-blood-ivory-behind-the-largest-ivory-smuggling-cases-in-china/.

Glaeser, Edward L and Andrei Shleifer. 2001. "A reason for quantity regulation." American Economic Review :431-435.

Goodwin, M. 2006. Black markets: the supply and demand of body parts. URL http://books. google. com/books?hl=en\&lr=\&id=EYqjk0ps jlUC\&oi=fnd\&pg=PT1\&dq=Black+Markets : +The+ Supply+and+Demand+of+Body+Parts\&ots=_IKmlh9e1u\&sig=_22QlfD8nIf-LmqMSQc1fHisuW4.

Heltberg, Rasmus. 2001. "Impact of the ivory trade ban on poaching incentives: a numerical example." Ecological Economics 36 (2):189-195.

Hsu, Tao, Andrew Lucas, Zhili Qiu, Mu Li, and Qingyuan Yu. 2014. "Exploring the Chinese Gem and Jewelry Industry." Gems \& Gemology 50 (1):2-29.

Hutton, J and G Webb. 2002. "Legal trade snaps back: using the experience of crocodilians in draw lessons on regulation of the wildlife trade." Crocodiles. Proceedings of the 16th Working Meeting of the Crocodile Specialist Group, IUCN (October):1-10.

IHS Global Insight. 2013. "IHS-Data Insight Web." URL http://myinsight.ihsglobalinsight. com/servlet/cats?imask=1\&pageContent=home.

Inciardi, J. and D. McBRIDE. 1989. "Legalization: A High-Risk Alternative in the War on Drugs." American Behavioral Scientist 32 (3):259-289.

International Fund for Animal Welfare. 2006. "Ivory Market in China -China Ivory Trade Survey Report." Tech. Rep. June, International Fund for Animal Welfare. URL http://www.ifaw.org/ sites/default/files/IvoryMarketinChinaChinaivorytradesurveyreport-2006.pdf.

Khanna, Jyoti and Jon Harford. 1996. "The ivory trade ban: Is it effective?" Ecological Economics 19 (2):147-155.

Koper, CS and JA Roth. 2002. "The Impact of the 1994 Federal Assault Weapons Ban on Gun Markets: An Assessment of Short-Term Primary and Secondary Market Effects." Journal of Quantitative Criminology 18 (3).

Kothari, SP and Jerold Warner. 2006. "Econometrics of event studies." Handbook of Empirical Corporate Finance 1:4-32. 
Kremer, Michael and Charles Morcom. 2000. "Elephants." The American Economic Review 90 (1):212234.

Kuziemko, Ilyana and Steven D Levitt. 2004. "An empirical analysis of imprisoning drug offenders." Journal of Public Economics 88 (9):2043-2066.

Lee, David S and Thomas Lemieux. 2010. "Regression Discontinuity Designs in Economics." Journal of Economic Literature 48:281-355.

Lemieux, A. and R. Clarke. 2009. "The International Ban on Ivory Sales and its Effects on Elephant Poaching in Africa." British Journal of Criminology 49 (4):451-471.

Levin, Dan. 2013. "From Elephants' Mouths, an Illicit Trail to China." URL http://www . nytimes.com/2013/03/02/world/asia/an-illicit-trail-of-african-ivory-to-china. html? pagewanted=all\&_r=0.

Levitt, Steven D. 2003. "Review of drug war heresies by MacCoun and Reuter." Journal of Economic Literature 41 (2):540-544.

Levitt, Steven D and Thomas J Miles. 2006. "Economic contributions to the understanding of crime." Annu. Rev. Law Soc. Sci. 2:147-164.

MacCoun, Robert J and Peter Reuter. 2001. Drug war heresies: Learning from other vices, times, and places. Cambridge University Press.

Martin, EB and Daniel Stiles. 2003. The ivory markets of East Asia. March. Nairobi, Kenya: Save the Elephants. URL https://54.249.186.214/nph-vzh.s/20/http/www.savetheelephants.org/ files/pdf/publications/2003Martin=26StilesEastAsiaIvoryMarkets . pdf.

Martin, R., D.H.M. Cumming, G. Craig, D. Gibson, and D. Peake. 2012. "Background study: Decisionmaking mechanisms and necessary conditions for a future trade in African elephant ivory." Tech. rep., CITES.

Milliken, T, RW Burn, and L Sangalakula. 2007. "The Elephant Trade Information System (ETIS) and the illicit trade in ivory: a report for the 14th meeting of the Conference of the Parties to CITES." Tech. rep. URL http://www. cites.org/common/cop/13/inf/E13-29-2A.pdf.

Milliken, T, RW Burn, Fiona Underwood, and L. Sangalakula. 2013. "ETIS Report of TRAFFIC." Tech. rep., CITES.

Nordhaus, William D. 1993. "Rolling the 'DICE': an optimal transition path for controlling greenhouse gases." Resource and Energy Economics 15 (1):27-50.

Nowak, Katarzyna, Andrew Dobson, Joyce Poole, Petter Granli, Paula Kahumbu, Phyllis Lee, Winnie Kiiru, Ponjoli Joram, Cyprian Malima, and Cynthia Moss. 2013. "Elephants are not Diamonds." URL http://www.theecologist.org/News/news_analysis/1800368/elephants_are_ not_diamonds.html.

OECD. 2013. "Geographical flows to developing countries (Geo Book)." URL http://stats.oecd. org/Index . aspx?DataSetCode=DACGEO.

Potter, Daniel and Christina Farr. 2015. "Would You Eat Artificial Shark Fin?" URL http://ww2 . kqed.org/futureofyou/2015/11/09/will-bioengineered-shark-fin-help-save-sharks/.

Qilu Weekly. January 25, 2014. "Why is 6.1 tons of ivory destroyed?" .

Rice, Mary. 2012. "Legal ivory trading severely undermines elephant conservation." URL http://www.theecologist.org/News/news_analysis/1669938/legal_ivory_trading_ severely_undermines_elephant_conservation.html.

Staedter, Tracy. 2015. "3D-Printed Synthetic Rhino Horns Could Save Rhinos." URL http://news.discovery.com/tech/biotechnology/ 3d-printed-synthetic-rhino-horns-could-save-rhinos-150624.htm.

Stiles, Daniel. 2004. "The ivory trade and elephant conservation." Environmental Conservation 31 (4):309-321. 
. 2012. "The 'Inconvenient Truth' about the ivory trade." URL http://www.theecologist. org/News/news_analysis/1690689/the_inconvenient_truth_about_the_ivory_trade.html.

Strange, Austin, Bradley C. Parks, Michael J. Tierney, Andreas Fuchs, Axel Dreher, and Vijaya Ramachandran. 2013a. "China's Development Finance to Africa: A Media-Based Approach to Data Collection." URL http://china.aiddata.org/.

Strange, Austin M, Brian O Donnell, Daniel Gamboa, and Bradley Parks. 2013b. "AidData's MediaBased Data Collection Methodology." Tech. Rep. April, Development Gateway, College of William and Mary, Brigham Young University. URL http://china.aiddata.org/MBDC_codebook.

Sullivan, ML. 2007. Making sex work: A failed experiment with legalised prostitution. URL http://books.google.com/books?hl=en\&lr=\&id=mzhgVt97eJcC\&oi=fnd\&pg=PR7\&dq=Making+ sex+work: +A+failed+experiment+with+legalised+prostitution\&ots=n-aBZBqCn3\&sig= A6u1e2Xwy1mF6yav-kqLy320ug4.

The Economist. 2008. "Round the horn: campaigners' fear for elephants, and their own credibility." The Economist URL http://www.economist.com/node/11751304.

Underwood, Fiona M., Robert W. Burn, and Tom Milliken. 2013. "Dissecting the Illegal Ivory Trade: An Analysis of Ivory Seizures Data." PLoS ONE 8 (10).

Wasser, Samuel, Katarzyna Nowak, Joyce Poole, John Hart, Rene L. Beyers, Phyllis Lee, Keith Lindsay, Gardner Brown, Petter Granli, and Andrew Dobson. 2010. "Response." Science 1634-1635.

Weitzman, Martin L. 1974. "Prices vs. quantities." The review of economic studies :477-491.

Wittemyer, G., J. M. Northrup, J. Blanc, I. Douglas-Hamilton, P. Omondi, and K. P. Burnham. 2014. "Illegal killing for ivory drives global decline in African elephants." Proceedings of the $N a$ tional Academy of Sciences 111 (36):1-5. URL http://www.pnas.org/cgi/doi/10.1073/pnas . 1403984111.

Wooldridge, Jeffrey M. 2010. Econometric analysis of cross section and panel data. MIT press.

World Bank. 2013. "World DataBank: World Development Indicators." URL http://databank . worldbank. org/data/home. aspx. 


\section{Online Appendix}

This Appendix contains five sections, with additional treatment of the following topics:

A Discrepancies between two official versions of PIKE data

B Outliers

C 2002 data quality

D Methods

E Comparison to aggregate statistics

\section{A Discrepancies between two official versions of PIKE data}

CITES made an Excel file of the official PIKE data (for 2002-2011) available through a Github site (https://Github.com/citesmike/mike_R_analyses/blob/master/pike_sc62.csv); this data was originally accessed May 7, 2013 and appears unchanged as recently as April 25, 2015. This file had the advantage of including raw data - that is, the number of total carcasses and number of illegal (poached) carcasses in each site. In July 2014, CITES published SC65 Inf. 1 (CITES, 2014), which, combined with previously published CITES documents (CITES, 2012), included all PIKE data from 2002-2013. This provided data we did not have previously: PIKE values for 2012-2013, as well as PIKE values from 2004-2011 which had only recently been reported to CITES (Julian Blanc, personal communication July 8, 2014). In addition, however, SC65 Inf. 1 also had several data values (for 18 site-years in total) that contradicted those from the Github file, listed in Table A1. Seventeen of these 18 discrepancies occurred at Asian MIKE sites. Despite repeated requests (July 8, 2014; July 21, 2014; August 18, 2014), CITES has not responded to explain those discrepancies or tell us which values are correct. CITES has also not (to our knowledge) made public an updated file of the raw data including the 2012-2013 data. We therefore use the latest data - those published in SC 65 Inf. 1-as the basis of our main analysis. Since the data provided in SC 65 Inf. 1 were presented as the PIKE value rounded to two decimal places and the total number of carcasses (and did not include the number of illegal carcasses), we inferred the number of illegal carcasses (where the Github file did not provide a value). For ten of the values in our final data set (where total carcasses were greater than 100), this required us to choose between two plausible values for the number of illegal carcasses (either of which would have resulted in the same reported rounded PIKE value in SC Inf. 1). In these cases, we estimated the number of illegal carcasses to be that which would result in a PIKE value closest to the decimal reported in SC 65 Inf. 1. In addition, since CITES has not disclosed the reason for the conflict between the Github data and SC65 Inf. 1 data, it is plausible that the Github data are correct. We therefore re-run our analyses with the Github values wherever there was a conflict and show in Figure A1 that there is no change in our results using this alternative data source. 


\section{Appendix Table A1: Discrepancies between two official versions of PIKE data}

\begin{tabular}{|c|c|c|c|c|c|c|}
\hline \multirow[b]{2}{*}{ Country } & \multirow[b]{2}{*}{ Site } & \multirow[b]{2}{*}{ Year } & \multicolumn{2}{|c|}{$\underline{\text { SC65 Inf. } 1 \text { Data }^{\dagger}}$} & \multicolumn{2}{|c|}{$\underline{\text { Github Data* }}$} \\
\hline & & & $\begin{array}{c}\text { Total } \\
\text { Carcasses }\end{array}$ & $\begin{array}{c}\text { Illegal } \\
\text { Carcasses }\end{array}$ & $\begin{array}{c}\text { Total } \\
\text { Carcasses }\end{array}$ & $\begin{array}{c}\text { Illegal } \\
\text { Carcasses }\end{array}$ \\
\hline India & Chirang Ripu & 2008 & 4 & 0 & 8 & 0 \\
\hline India & Chirang Ripu & 2009 & 7 & 4 & 5 & 0 \\
\hline India & Deomali & 2006 & 3 & 3 & 2 & 0 \\
\hline India & Dihing Patkai & 2006 & 6 & 0 & 1 & 0 \\
\hline India & Dihing Patkai & 2008 & 3 & 1 & 5 & 1 \\
\hline India & Dihing Patkai & 2009 & 2 & 0 & 3 & 0 \\
\hline India & Eastern Dooars & 2007 & 20 & 0 & 15 & 0 \\
\hline India & Eastern Dooars & 2008 & 15 & 0 & 15 & 1 \\
\hline India & Eastern Dooars & 2009 & 12 & 0 & 2 & 0 \\
\hline India & Garo Hills & 2006 & 6 & 3 & 4 & 0 \\
\hline India & Garo Hills & 2008 & 9 & 2 & 6 & 1 \\
\hline India & Garo Hills & 2009 & 4 & 3 & 8 & 3 \\
\hline Malaysia & Kluang & 2007 & 0 & 0 & 1 & 0 \\
\hline Malaysia & Kluang & 2009 & 1 & 1 & 2 & 1 \\
\hline India & Mayurbhanj & 2006 & 17 & 3 & 1 & 0 \\
\hline India & Mysore & 2006 & 57 & 24 & 3 & 1 \\
\hline China & Xishuangbanna & 2006 & 2 & 1 & 1 & 0 \\
\hline Nigeria & Yankari & 2011 & 4 & 4 & 1 & 1 \\
\hline
\end{tabular}

${ }^{\dagger}$ Ref. (CITES, 2014). *Accessed April 25, 2015.

\section{B Outliers}

We drop three extreme and influential outliers (see Figure A2). In 2009, a drought in Kenya caused legal mortality at two sites (Tsavo and Samburu-Laikipia) to exceed 200 at each site. These represent $9.6 \sigma$ and $11.1 \sigma$ outliers. In 2012, one site in Botswana (Chobe) exhibited legal mortality above 300 (cause unknown), a $12.9 \sigma$ outlier. These three observations represent $0.5 \%$ of our sample (after 2002 is dropped) but exert substantial influence on our estimates even though they provide little additional information on black market behavior, so they are dropped from our sample.

In Appendix E, we demonstrate that failing to drop these observations provides a highly misleading picture aggregate PIKE responses using a fully aggregated measure of PIKE that has been used by some prior analyses. Our approach is much less sensitive to these outliers, as shown in Figure A1, but they are removed from the sample nonetheless as they provide little additional information relative to the potential distortion they introduce. 

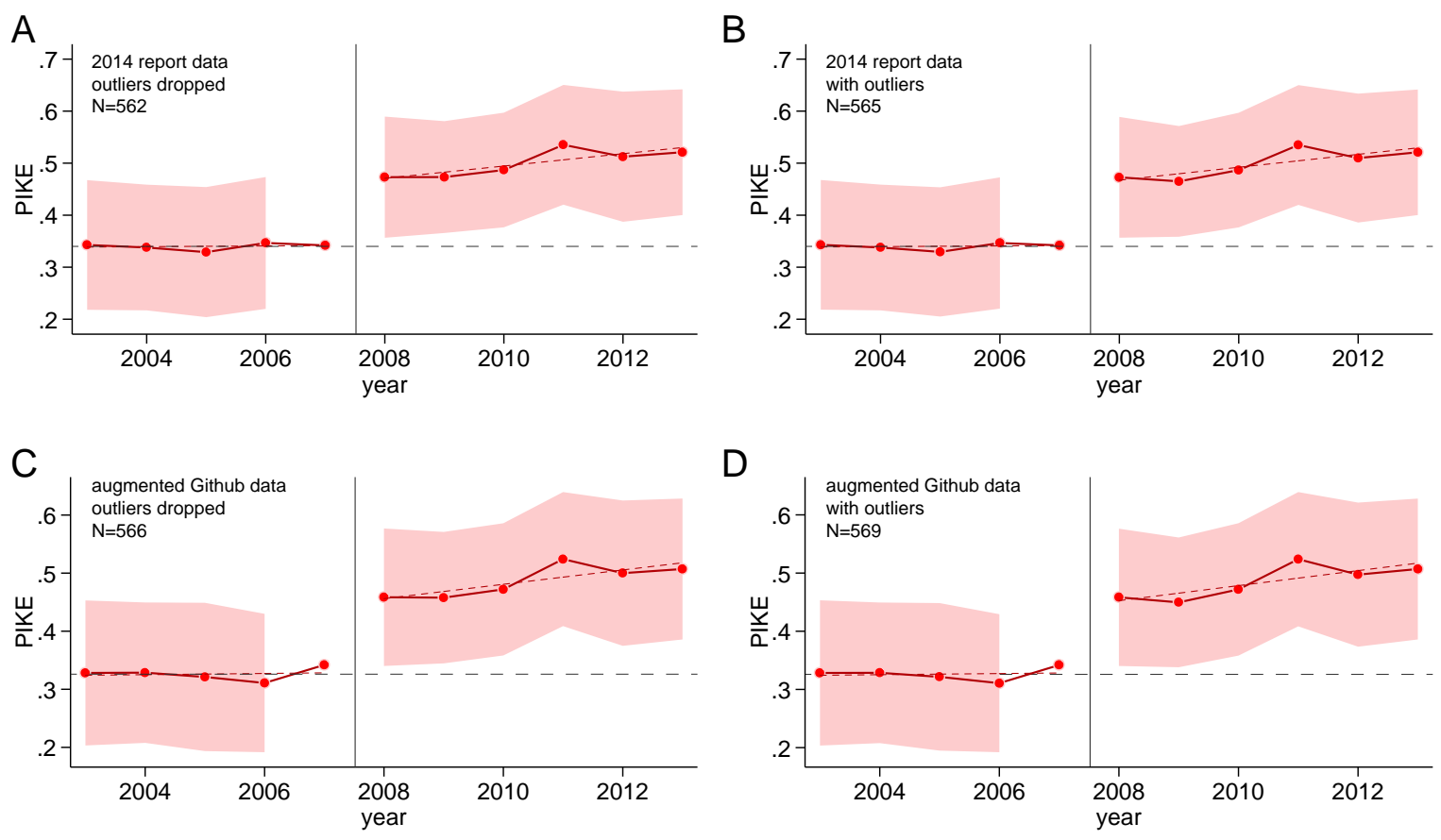

Appendix Figure A1: Effect of legal ivory sale on PIKE using alternative CITES data file and including outliers. (A) Same as Figure 2B in the main text. (B) Same as A, except including the three outliers described in Section B. (C) Same as A except using publicly available data posted on Github for 2003-2011, instead of CITES report data. (D) Same as B, except using the Github data.

\section{2002 data quality}

Widespread surveillance of illegal elephant killing began with the deployment of the MIKE surveillance system in 2002. Because the system was being brought online during 2002, annual observations recorded for the year 2002 exhibit numerous properties that make them qualitatively different and statistically incomparable to observations in later years. To our knowledge, the reliability of annualized 2002 PIKE data has not been previously discussed or documented, so we do both here. Ultimately, concerns over both reliability and the failure of sites to sample a complete and comparable 12 month interval during 2002 leads us to drop 2002 observations from our main analysis. However, including 2002 in our analysis does not change our central conclusions, as demonstrated in the main text.

Issues arising from the 2002 PIKE data include:

- Only 19 sites report any data in 2002, shown in Figure A3A. During the remaining sample, an average of 51.1 sites reported data each year with a standard deviation of 6.6 sites reporting. The next lowest reporting year was 2005, when 43 sites reported data. The count of sites reporting in 2002 is thus a $4.9 \sigma$ outlier. The low number of sites reporting is likely due to the lag required for many sites to be brought online after the start of the program.

- Of the 19 sites reporting in 2002, 12 began data collection after January. Thus, the annual carcass counts supplied by these sites do not represent a complete 12-month long total and thus cannot 


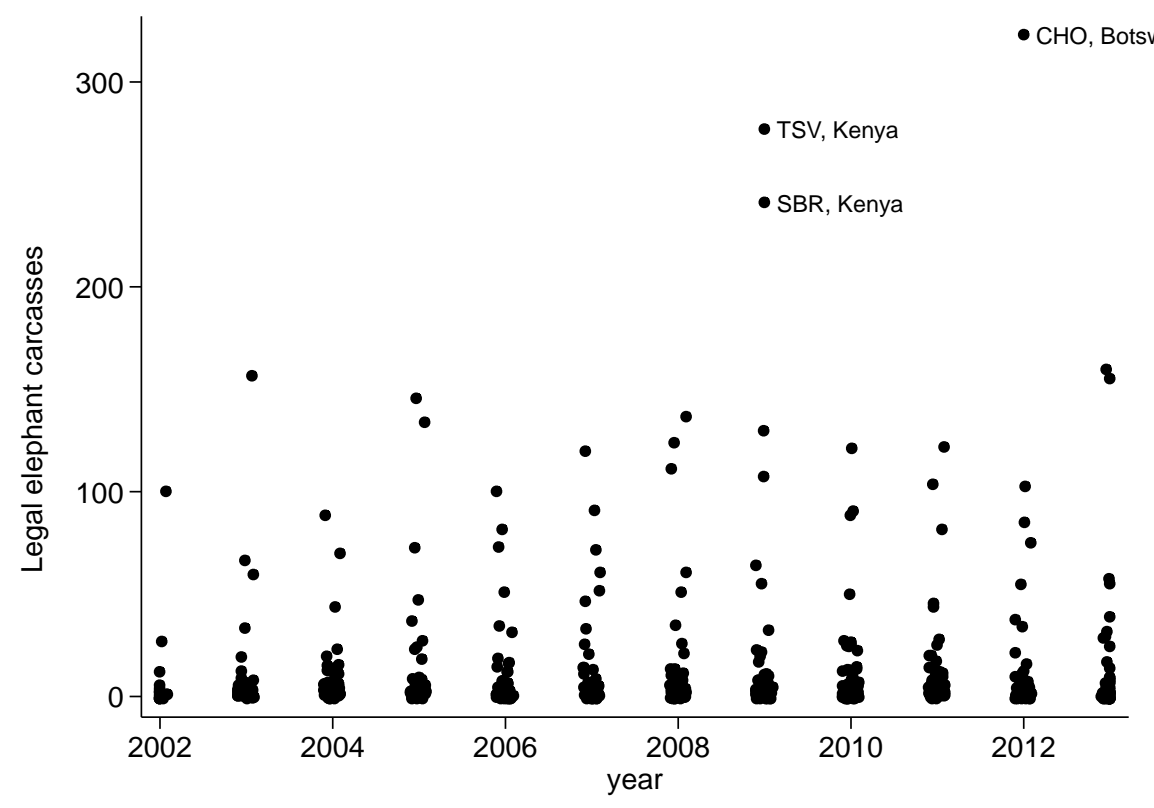

Appendix Figure A2: Counts of legal elephant kills in range states (jittered). Legal elephant kills in range states are used to normalize counts of illegally killed elephants in the PIKE measure, to account for the effort of surveyors and the changing likelihood of discovering any elephant carcass. In 2009, just following the delivery of legal ivory to China and Japan, two sites in Kenya reported discovering very high counts of legal elephant deaths (9.6 $\sigma$ and $11.1 \sigma$ outliers) due to drought (Burn, Underwood, and Blanc, 2011). In 2012, one site in Botswana reported even higher legal mortality

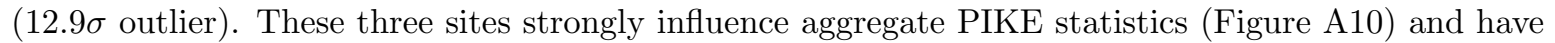
moderate influence on our baseline regression model. These three outliers are dropped from the sample in our main estimation.

be compared to later years where 12-month totals are reported, as they will be systematically lower. Because elephant mortality and poaching patterns may exhibit strong seasonality that differs between regions, this introduces an unknown bias. We have requested monthly PIKE data by site to correct for this issue, but have been denied access on legal grounds (over email May 10, 2013, reiterated in phone conversation with Julian Blanc, 2013).

- Of the 19 sites reporting in 2002, 53\% report exactly 1 legal carcass (Figure A3B). Across years, the average fraction of sites with exactly one legal carcass is $21 \%$ with a standard deviation of $6.4 \%$. The next highest year is $29 \%$ of sites reporting one legal carcass. This means that 2002 is also a $4.9 \sigma$ outlier in the number of sites reporting exactly one legal carcass, which is extremely unlikely to occur due to natural sampling error and variability $(\mathrm{p}<0.01)$, even when accounting for a trend in these values. We do not know why a majority of sites report exactly one legal carcass and no illegal carcasses in the first year of the MIKE program when no other year exhibited such a pattern.

- The large fraction of sites reporting one legal carcass in 2002 seems additionally exceptional when 

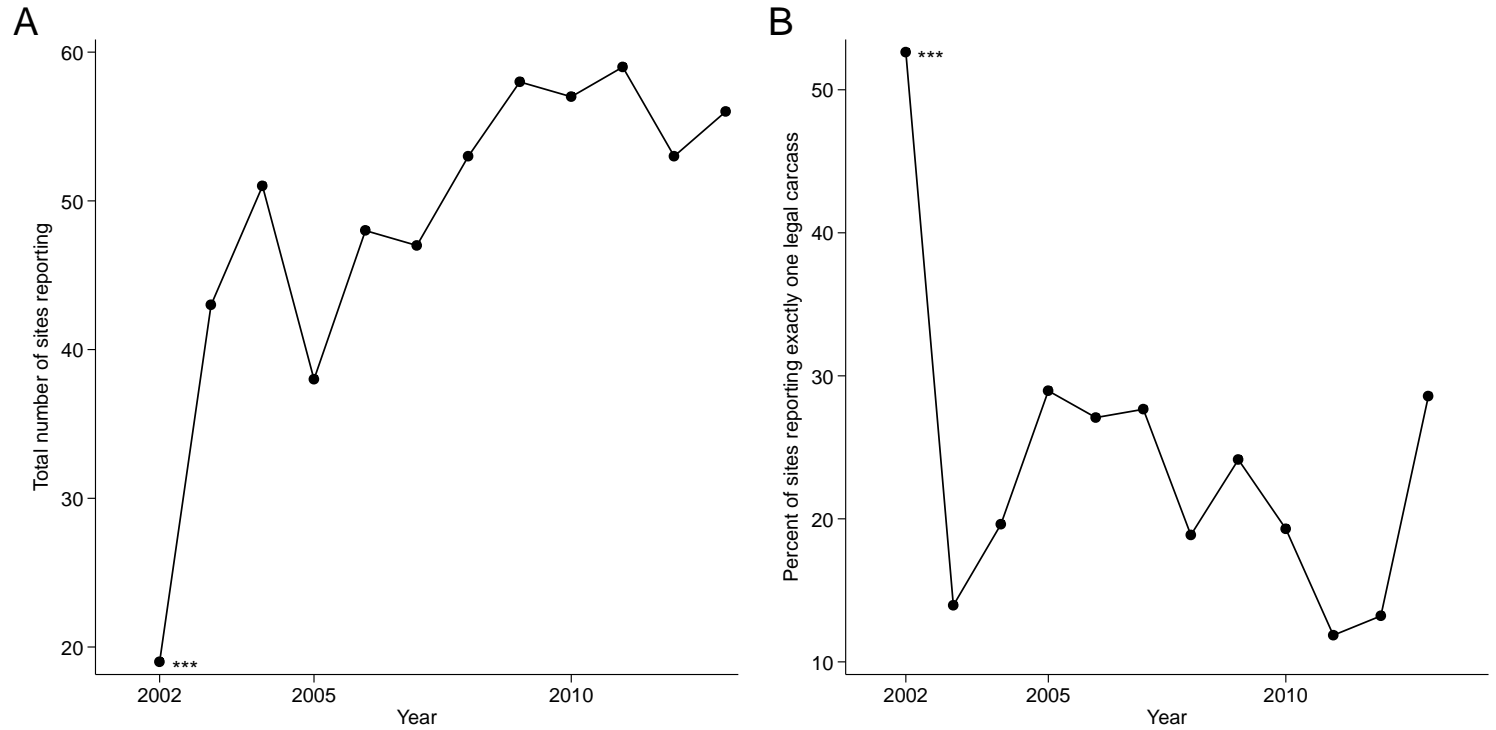

Appendix Figure A3: PIKE data collection irregularities in 2002. (A) The total number of MIKE sites reporting data in each year. The low number of reporting sites (19) in the first year of the program is unlikely to be explained by normal variability in data collection $(p<0.01)$. Moreover, twelve of the nineteen sites reported not collecting a complete year of data in the first year of operation (CITES, 2002a). (B) The percent of reporting sites that reported finding exactly one legal carcass in each year. The high fraction of sites $(53 \%)$ reporting exactly one legal carcass and no illegal carcasses is unlikely to be explained by normal variability $(\mathrm{p}<0.01)$.

compared to the number of sites reporting zero or two carcasses, in comparison to other years in the sample. Figure A4 displays the distribution of legal carcass counts across years. Across other years, the number of sites reporting zero legal carcasses is generally close to the number of sites reporting one legal carcass, and moderately close to the number of sites reporting two legal carcasses. However, in 2002 there is an extremely large difference between the number of sites reporting one legal carcass and either two or zero legal carcasses.

- The distribution of illegal carcasses in 2002 seems similarly abnormal, with 13 of 19 sites reporting zero illegal carcasses and only two sites reporting one carcass. Figure A5 displays the distribution of illegal carcasses for each year. In other year, the number of sites reporting zero and one illegal carcass is always much closer than in 2002.

- The combined effect of abnormal reporting for both legal and illegal carcasses in 2002 generates a highly irregular distribution of PIKE across sites. Figure A6 compares the distribution of PIKE between 2002 and 2003, as well as the pooled sample of all other years. The large number of sites reporting zero illegal carcasses and one legal carcasses causes the mass of observations to stack at PIKE $=0$. In the following year, the distribution shifts abruptly to have roughly equal mass at PIKE $=1$, with roughly uniform mass between zero and one. This pattern persists for all subsequent periods, suggesting that the distribution in 2002 is an irregularity.

We do not know why the 2002 data are so qualitatively and quantitatively different from data in 


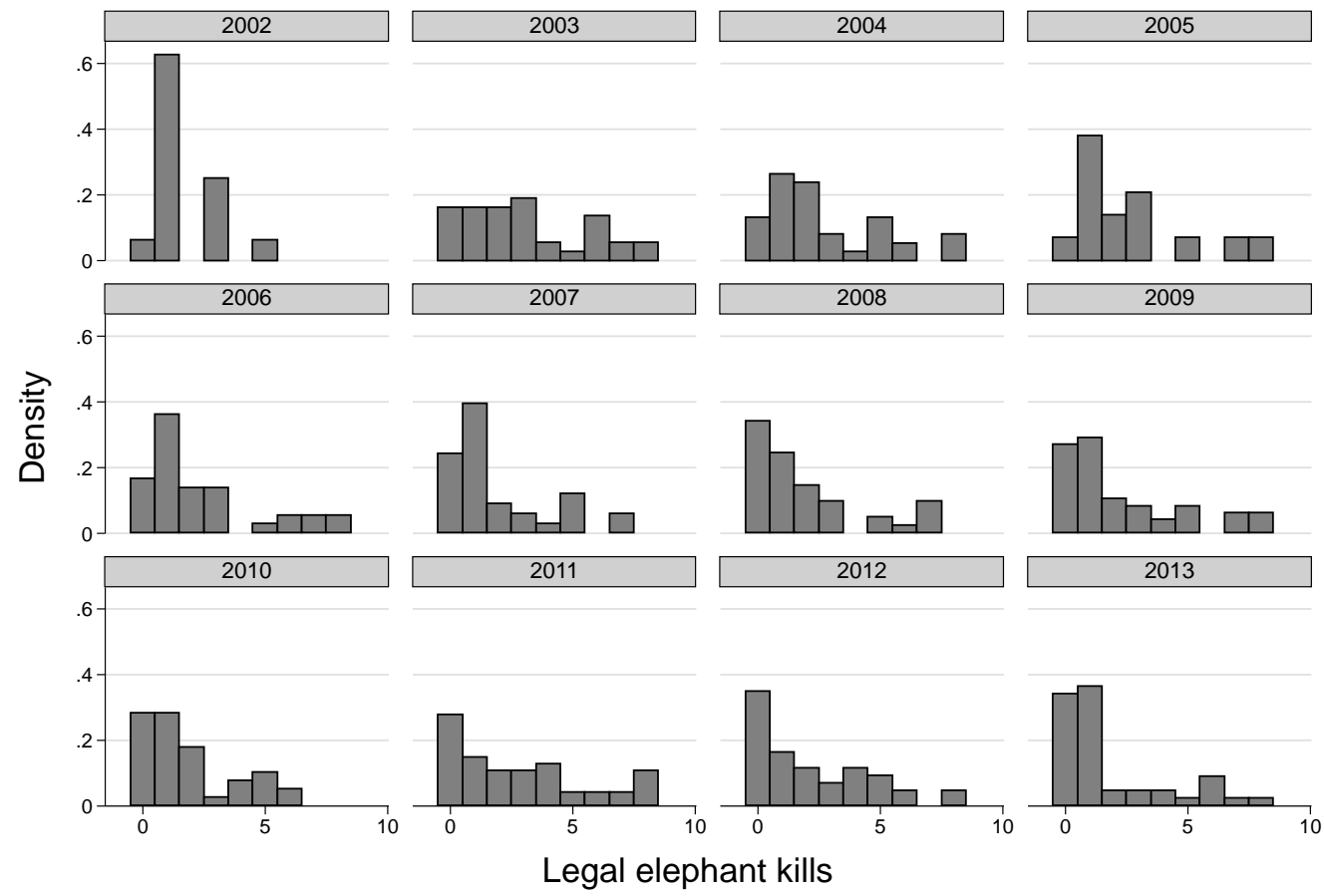

Appendix Figure A4: Annual distribution of legal elephant carcass counts. Histogram of the number of legal carcasses reported each year for sites reporting ten or fewer legal carcasses. Of sites reporting in 2002, an abnormally large fraction reported exactly one legal carcass and an unusually small number of sites reported zero.

subsequent years when distributional patterns stabilized. Many survey programs exhibit large data irregularities in their first round, so perhaps the irregular patterns in 2002 are unsurprising. In many cases, it is observed that surveyors collect data differently or make errors during the initial rollout of a program, sometimes because training and experience accumulate with time. In other cases, there is political pressure to demonstrate that at least some survey data is collected in a first round, even if its quality may be compromised (Bamberger, Rugh, and Mabry, 2011). We do not know whether these or other factors contributed to observed irregularities in the first year of PIKE data. It is possible that the incomplete sampling of months in the first year of surveillance, combined with seasonality in legal and illegal mortality, explains most of the irregular pattern in 2002.

Regardless of the source of these irregularities, the data in 2002 is known to be incomparable to later years because of the uneven sampling of months (CITES, 2002a), so we drop it from our main sample. Below we test whether our results hold if 2002 is included and find that its inclusion has limited effect. The main impact of including 2002 in the sample is that it increases our estimated sampling error (because irregular observations have large residuals) and it biases the pre-sale trend substantially. 


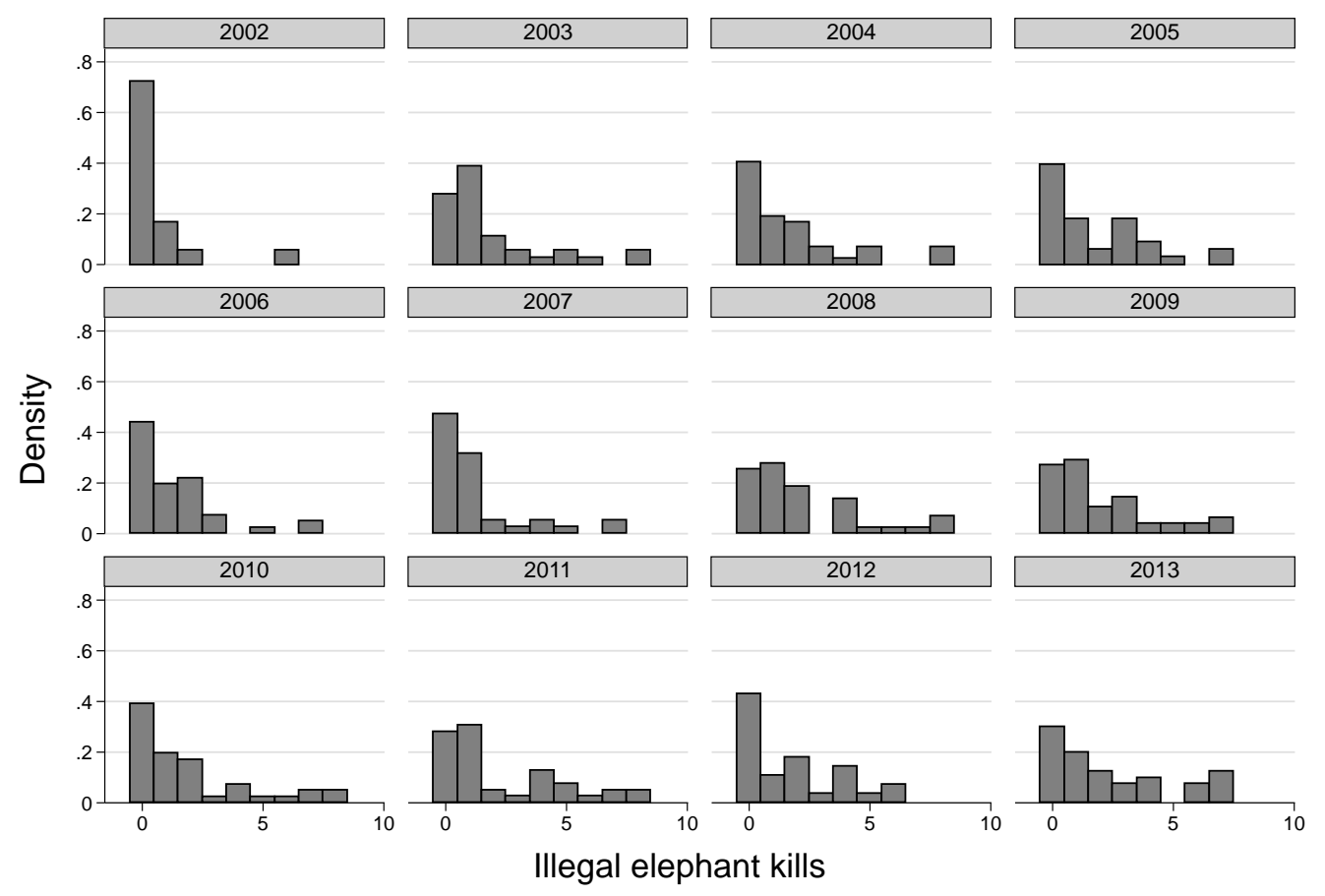

Appendix Figure A5: Annual distribution of illegal elephant carcass counts. Histogram of the number of illegal carcasses reported each year for sites reporting ten or fewer illegal carcasses. Of sites reporting in 2002, an abnormally large fraction reported zero illegal carcasses and an unusually small number of sites reported one.
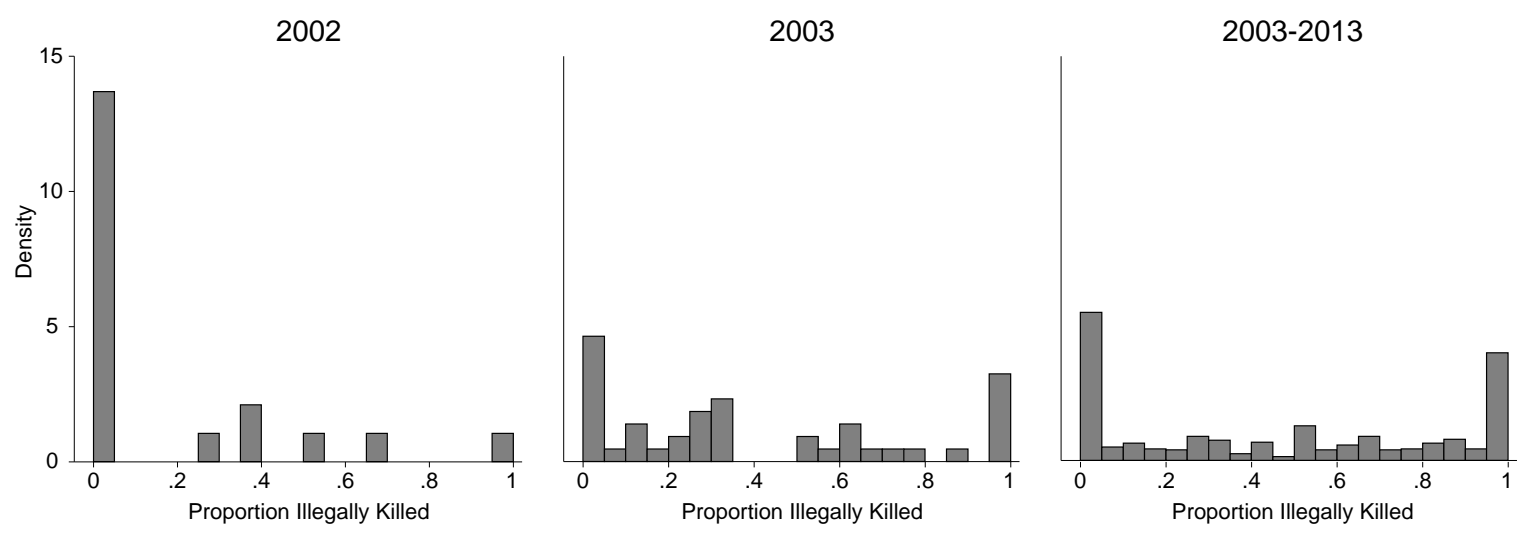

Appendix Figure A6: Extreme and irregular distribution of PIKE in 2002. Histogram of raw PIKE values in 2002 compared with 2003 and the average distribution across the remaining sample. The distribution of PIKE in 2002, the first year of data collection, differs dramatically from the immediately following year (2003), which exhibits a distribution similar to the overall sample (2003-2013). 


\section{Methods}

\section{Intuition of the core approach}

It is widely understood that local economic conditions, geography, the presence of roads, the quality of law enforcement, and numerous other factors influence the intensity of poaching at specific sites. It is thus imperative that the influence of these factors are accounted for when examining global trends. In particular, because the sampling of sites is incomplete and often interrupted it is possible that changes in global trend estimates could be confounded by a change in the composition of sites reporting PIKE data. For example, if the representation of sites with weaker governance and higher poaching in the sample systematically increases over time, it would appear though there is a secular upward trend in PIKE if this factor is not accounted for. In principle, one could account for such a bias by "controlling" for covariates. However, it is generally impossible to explicitly to account for all potential factors that influence poaching, and any list of control variables in a regression model is open to the critique that it is incomplete and may have omitted key variables. This critique cannot be addressed until the omitted variable is collected and included in the model, at which point another potential omitted variable might be identified, raising concern yet again. The situation initially appears hopeless, and it appears even more hopeless when one considers that additively "controlling" for these variables in a standard regression model makes the strong assumptions that the effect of each control variable is fixed across locations-or in more sophisticated models that these effects satisfy slightly weaker distributional assumptions. Fortunately, there is an alternative approach that is simple, general, remarkably robust, and, most importantly, feasible.(Wooldridge, 2010)

We conceptualize poaching levels as some unknown and potentially nonlinear function of various local, national, and global factors, some of which may be observable and others which might not be. For site $i$ located within country $j$ observed in year $t$, we could stylize this model as

$$
\begin{aligned}
& P I K E_{i j t}=\underbrace{f_{i}\left(\text { site_geography }_{i}, \text { local_econmic_conditions }_{i}, \text { national_institutions }_{j}, \text { culture }_{j}, \text { etc. }\right)}_{\text {site-specific effects }} \\
& +\underbrace{g\left(\text { global_policy }_{t}, \text { oil_prices }_{t}, \text { etc. }\right)}_{\text {global trends }}+\underbrace{h\left(\text { national_policies }_{j t}, \text { economic_trends } s_{j t}, \text { etc. }\right)}_{\text {country trends }}+\epsilon_{i j t}
\end{aligned}
$$

recognizing that the functions $f_{i}(),. g($.$) , and h($.$) may be unknown. Furthermore, f_{i}($.$) may differ$ between locations, since it is possible that various factors interact in complex ways such that incremental changes in any one factor do not influence PIKE identically across different contexts. Models that explicitly "control" for various factors, such as income or governance, make assumptions about the form of these functions. If we do not make such assumptions, but instead assume that site-specific factors evolve very slowly, we can estimate $f_{i}($.$) as the average PIKE observed during the period of$ observation in site $i$, known as a "site fixed effect." A site fixed effect non-parametrically captures all the site-specific factors that do not change during the period of observation but that may affect PIKE at a site (Wooldridge, 2010). Importantly, these parameters also capture any country-specific variables, such as national institutions, governance and culture. The simplest model that isolates these 

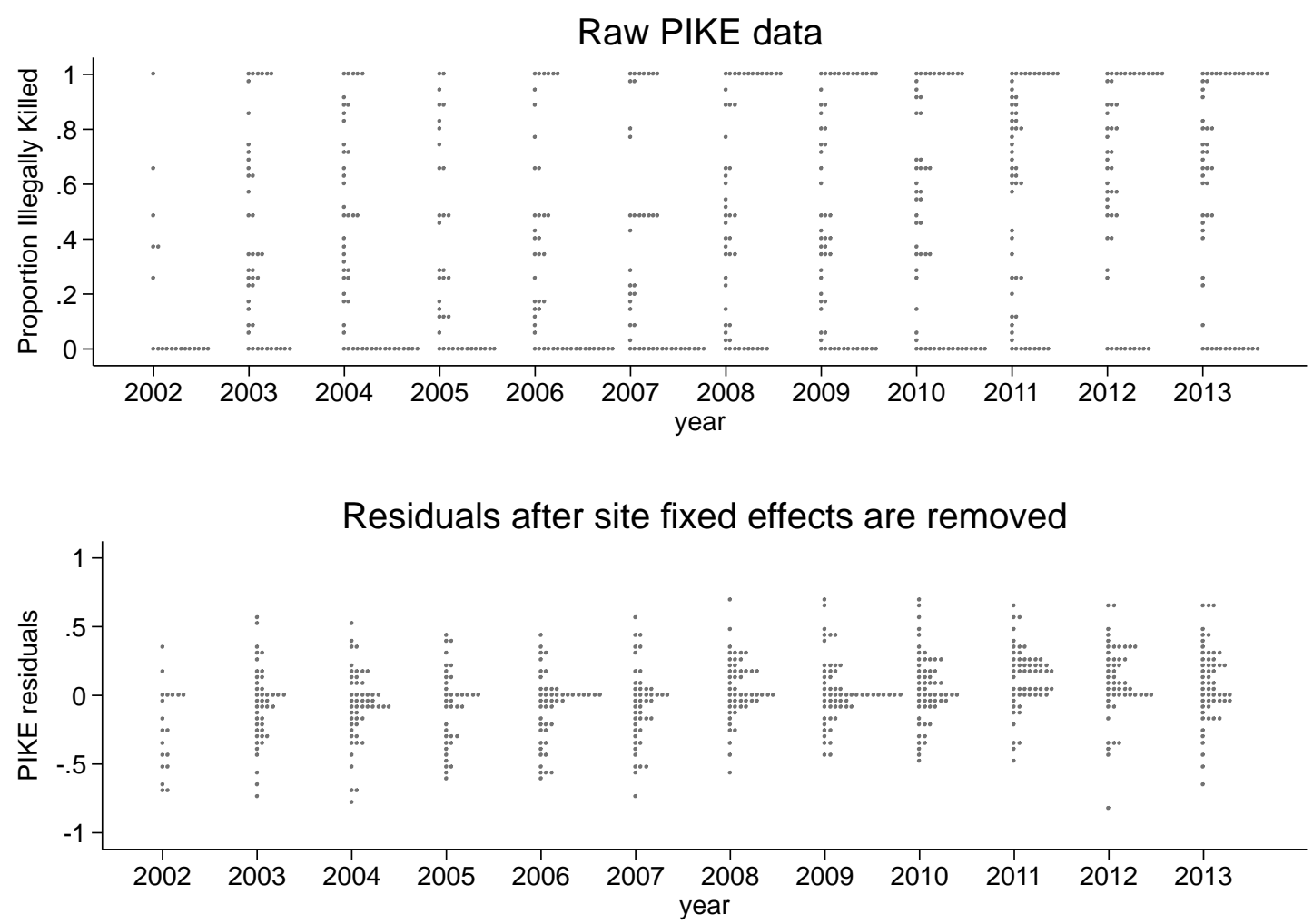

Appendix Figure A7: Removing site-specific averages from raw data. All statistical models used in this analysis remove site-specific averages from the data using site fixed effects. This transformation removes average cross-site differences in reported poaching rates do to geography, culture, economics, surveillance, etc. It also removes biases due to the timing of site entry and exit from the sample. The raw distribution of PIKE is shown for each year in the top panel. Bottom panel shows the distribution of PIKE residuals after site averages are removed via regression on site fixed effects. Notably, the distribution of residuals is more approximately normal than the raw data.

site-specific factors from trending factors captured in $g($.$) and h($.$) is$

$$
P I K E_{i j t}=\mu_{i}+\gamma_{t}+\epsilon_{i j t}
$$

which is Equation 5 in the main text. The site-specific constants $\mu_{i}$ are site fixed effects that account for all constant local factors, such as baseline mortality, climate, socio-economic conditions, and levels of human-elephant conflict. These site fixed effects remove any bias in trends due to compositional changes in which sites report data in different years. The annual constants $\gamma_{t}$ describe global changes in poaching $g($.$) that are common to all sites. If global black markets adjust abruptly to the legal sale$ of ivory, this effect will be measured by a change in $\gamma$ for years following the sale. $\epsilon$ is unexplained residual variation, which may include national changes $h($.$) that are independent of global trends as$ well as various uncorrelated local factors that alter PIKE across years within a site. 
After estimating this equation, we remove the site fixed effects $\mu_{i}$ from the data so only the demeaned data $\left(\gamma_{t}+\epsilon_{i j t}\right)$ remains. We plot the distributions of this otherwise raw data in Figure $2 \mathrm{~A}$ of the main text. After simply removing site-specific means, the discontinuous jump in the distribution of annual PIKE in 2008 is readily visible. Dashed lines depict trends in different centiles of the annual distributions of $\epsilon_{i j t}$, which exhibit clear discontinuities except at the 95th centile. With only minimal data processing (i.e. demeaning the data by site), the effect of the experimental sale is apparent.

In Figure 2B of the main text we plot the estimates of $\gamma_{t}$, which capture all globally coherent shifts in PIKE in each year, represented by $g($.$) in Equation 9. If global policies or events cause systematic$ changes in PIKE around the world, this will result in a shift in the distribution of PIKE (Figure 2A) and a change in the mean of this distribution (Figure 2B).

\section{Interpretation}

The results in Figure 2 and regression results presented in Table 2 describe outcomes from a global experiment, which are analyzed and interpreted in the framework of an "event study." Event study research designs are a standard econometric approach (Kothari and Warner, 2006), used most commonly in finance, to measure the effect of an exogenous event on some dependent variable. Event studies are usually considered "quasi-experiments" because the analyst is usually incapable of experimentally manipulating the timing of the treatment, although in this case the timing of the legal sale was determined by CITES and originally portrayed as an actual experiment.

Event studies identify the causal effect of events on outcomes by measuring whether an outcome variable exhibits discontinuous behavior at the moment of treatment. So long as potentially confounding variables are continuous and "smooth" throughout the event, conditional on covariates, then any discontinuous behavior in the outcome at the time of the treatment can be attributed to the treatment event (Kothari and Warner, 2006; Angrist and Pischke, 2008). For example, in standard applications analysts examine stock prices over time and evaluate whether abnormal returns jump discontinuously at the moment that a firm announces new information about profits. So long as other factors that affect stock returns do not also change discontinuously at the time of the announcement, then we can infer that the discontinuity observed at the moment of the announcement is attributable to the announcement. Potential confounding factors may be trending upward or downward at the time of the announcement, however so long as these trends are "smooth" then their effects on the outcome can be removed by de-trending the data (as in Equation 6-7). Moreover, such trends will not affect the estimated size of the discontinuity so long as they are appropriately accounted for with a sufficiently flexible trend structure. However, if confounders also change abruptly at the moment of treatment this may confound causal inference. In the example of stock returns, if government regulation is announced at the same time that a firm announces information on profits, it will not be possible to determine whether an abrupt change in stock prices are due to the government announcement or the firm announcement. Because this assumption is critical for inference, we explicitly test it for a variety of plausibly important covariates in the main text. We do not find clear evidence of discontinuities among a variety of relevant covariates, although it is of course impossible to test all potential confounders around the globe. Importantly, any confounding event that would bias our estimates must (i) occur abruptly in 2008, (ii) affect PIKE around the globe in a coherent and immediate way that 


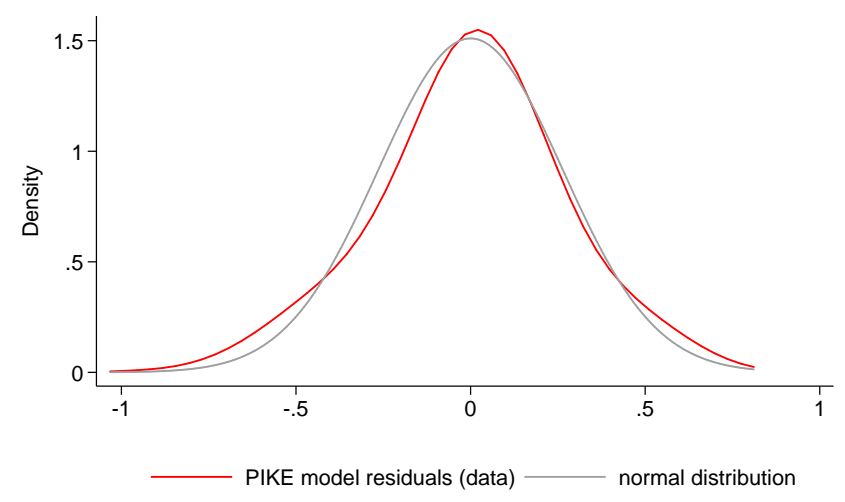

Appendix Figure A8: Testing for normality. PDF of the residuals of our benchmark model (Equation 5), comparing the distribution of residuals against a normal distribution. Residual PIKE variation in $\epsilon_{i j t}$ appears to be well approximated by a normal distribution.

persists through 2013, (iii) not occur in other years between 2003-2013. We do not observe any obvious confounders related to the CITES timeline or other global events, although it is always possible that future work may uncover an important potential confounder.

\section{Checking assumptions of a linearized approach}

In the context of Equation 9, there are various approaches for ensuring that our estimates for the size of the discontinuity are not biased by different types of trends at the global, national, or site level. These are explained and evaluated below and in Section 6 of the main text. These approaches are able to account for changes in conditions around the world or other events that might alter the global distribution of PIKE. Our results are unchanged under these various alternative approaches.

Other analyses of the PIKE data have used a variety of alternative statistical models (e.g. (Burn, Underwood, and Blanc, 2011)). Here, we opt for the simplest and most transparent model that adequately accounts for critical patterns in the data (Equations 5-7). This approach allows us to clearly see what is happening in the data and does not obscure what are relatively simple patterns with complex transformations. (We verify that our findings are robust to more structured approaches in Table 4 of the main text.) Earlier analyses of the PIKE data have focused on using nonlinear models that constrain PIKE to be bound between zero and one inclusive (the interval $[0,1]$ ), because PIKE values are constrained by construction. The sample distribution of PIKE is displayed in Figure A6, and the stacking of observations at zero and one are also conspicuous features that might be considered in a statistical model. Interestingly, however, linear statistical models perform remarkably well in this context and have multiple advantages to nonlinear approaches. Nonlinear approaches are substantially more difficult to interpret, generally require stronger assumptions regarding the data generating process, and do not allow all of the data to be used.

The key reason why linear models perform so well in this context is because individuals sites almost never exhibit variation in PIKE that spans the full range between zero and one. Sites with high poaching rates tend to always have high poaching rates, and visa versa for low or moderate poaching 


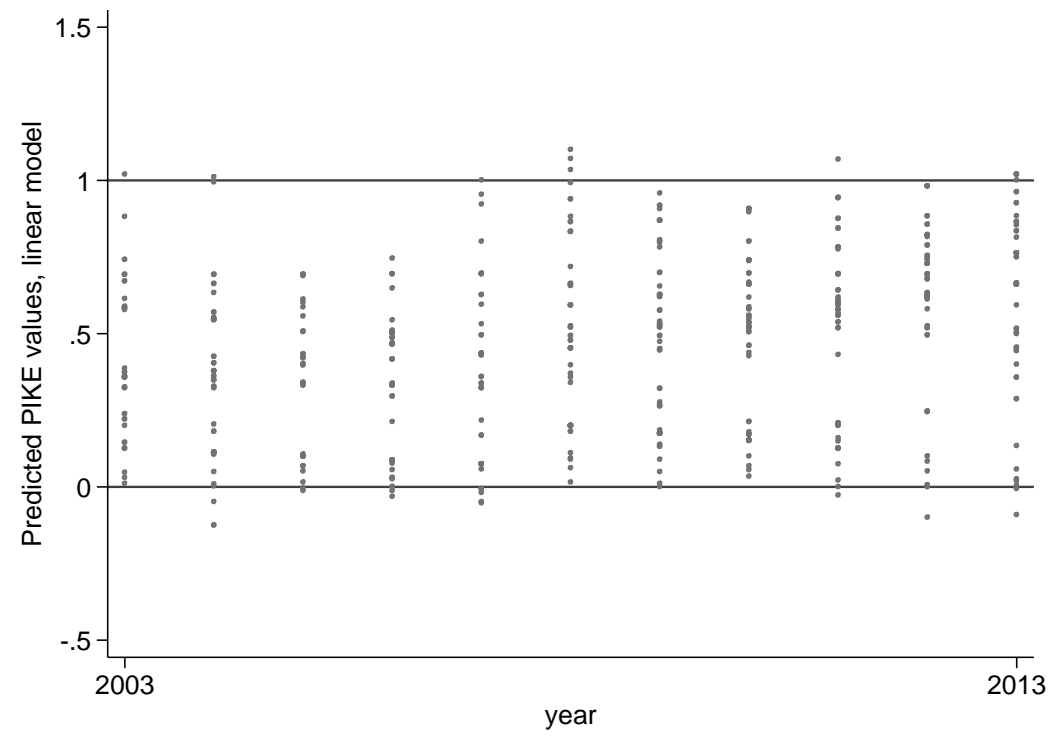

Appendix Figure A9: Checking linear model predictions. Actual PIKE values are bound to lie between zero and one (inclusive) by construction. The linear models used here do not constrain predicted values to lie on this interval, so predicted values must be checked. Predicted observations using our complete model (Equation 7) are plotted for all observations in the sample. $94.7 \%$ of predicted values lie on the interval $[0,1]$. 30 out of 563 observations $(5.3 \%)$ are outside this interval. Of these 30 predictions, the average distance from the $[0,1]$ interval is 0.0367 , with standard deviation 0.0379 and maximum 0.125. Alternatively, if a nonlinear logit fixed effects model that constrains predictions to $[0,1]$ is used, no predictions lie outside these bounds but $32.1 \%$ of the sample must be dropped.

rates. Thus, variation in PIKE within a site tends to be modest and therefore well approximated by linear functions, as suggested by Taylor's Theorem. Our approach only draws inferences from withinsite changes in PIKE because average site-level poaching rates are absorbed by the site fixed effect $\mu_{i}$. That is, all remaining variations has mean zero for each site and inference is based on variations over time around this mean. Because variations within a site are much smaller than differences in average poaching rates between sites, Taylor's Theorem applies and linearization describes variation in the data well.

To see this, Figure A7 displays the raw annual distribution of PIKE (top panel) which at first glance appears to be strongly affected by bounds at zero and one. However, once site-specific averages $\left(\mu_{i}\right)$ are removed (bottom panel) the distribution of data in each year look approximately normal with a shifting mean ${ }^{23}$. This is why the remaining variation is well-modeled by $\gamma_{t}+\epsilon_{i j t}$. The variance across years appears to be relatively consistent (homoscedasticity) and is mean zero conditional on annual averages. If the disturbances $\epsilon_{i j t}$ were independent and identically distributed, then Ordinary Least Squares (OLS) would be the Best Linear Unbiased Estimator, as indicated by the Gauss-Markov Theorem, meaning that no other estimation procedure is able to use the available data more efficiently than OLS. It is unlikely that the disturbances $\epsilon_{i j t}$ are entirely independent across observations within

\footnotetext{
${ }^{23}$ Some stacking at zero occurs because some sites always report the same PIKE values (often either 0 or 1 ), so there is no within-site variation at those sites.
} 
each country, since country-level policies and conditions may change the spatial distribution of poaching within a country or the overall level of poaching within portions of a country or the serial correlation of poaching within a site or subregion. Thus our implementation of Equation 5 does not assume independence across observations within a country and instead non-parametrically estimates a blockdiagonal variance-covariance matrix for residuals $\epsilon_{i j t}$ where errors for any pair of observations in the same country is not assumed to be zero. This approach is known as "clustering" observations by country (Bertrand, Duflo, and Mullainathan, 2004). Notably, this approach accounts for arbitrary forms of spatial and temporal correlation within each country and is robust to heteroscedasticity.

Normality of the residual $\epsilon_{i j t}$ is not essential for OLS to produce unbiased and efficient estimates of $\beta$. Nonetheless, checking that disturbances $\epsilon_{i j t}$ are normal is reassuring since it often suggests that variation unexplained by a model is consistent with random noise and it is an assumption that is used

to estimate critical values for uncertainty in finite samples. Figure A8 displays an empirical PDF for our residual variation and indicates that it is indeed extremely close to normally distributed.

\section{Issues arising with alternative nonlinear probability models}

Linear probability models are useful because they are transparent, they allow us to non-parametrically account for a variety of spacio-temporal patterns, and they approximate the data well. The central drawback of linear probably models is that predicted probabilities can exceed 1 or fall below 0 , which are not valid probabilities. Thus, an important check when using these models is to examine whether the model behaves poorly near these bounds. Figure A9 displays predicted values for our linear probability model. Out of 563 observations, only 30 are outside this interval. Of these 30 predictions, the average distance from the $[0,1]$ interval is 0.0367 , with standard deviation 0.0379 and maximum 0.125. Alternatively, if a nonlinear logit fixed effects model that constrains predictions to $[0,1]$ is used, no predictions lie outside these bounds but $32.1 \%$ of the sample is unusable in nonlinear fixed effects models and must be dropped. In the main text, we explore alternative statistical models that do not drop this much data but which do implicitly constrain PIKE to values between 0 and 1 . These alternative approaches do have other weaknesses, but none as severe as discarding $32 \%$ of the data. Importantly, under these alternative approaches, our results remain unchanged.

\section{E Comparison to aggregate statistics}

In the main text, we estimated the average effect of the legal ivory sale on PIKE in the average site or country. That is, the presented results were site-level or country-level effects representing local changes in expected PIKE, conditional on the sale. However, it would be possible to compute a globally aggregated PIKE measure and to examine whether it responds to the sale. Rather than computing a local measure of PIKE, one could sum illegal carcasses and total carcasses globally, dividing the two to construct an aggregate PIKE measure

$$
\text { Aggregate_PIKE } E_{t}=\frac{\sum_{i} \text { illegal_carcasses }_{i t}}{\sum_{i}\left(\text { legal_mortality }_{i t}+\text { illegal_carcasses }_{i t}\right)}
$$


A

Global aggregate statistics

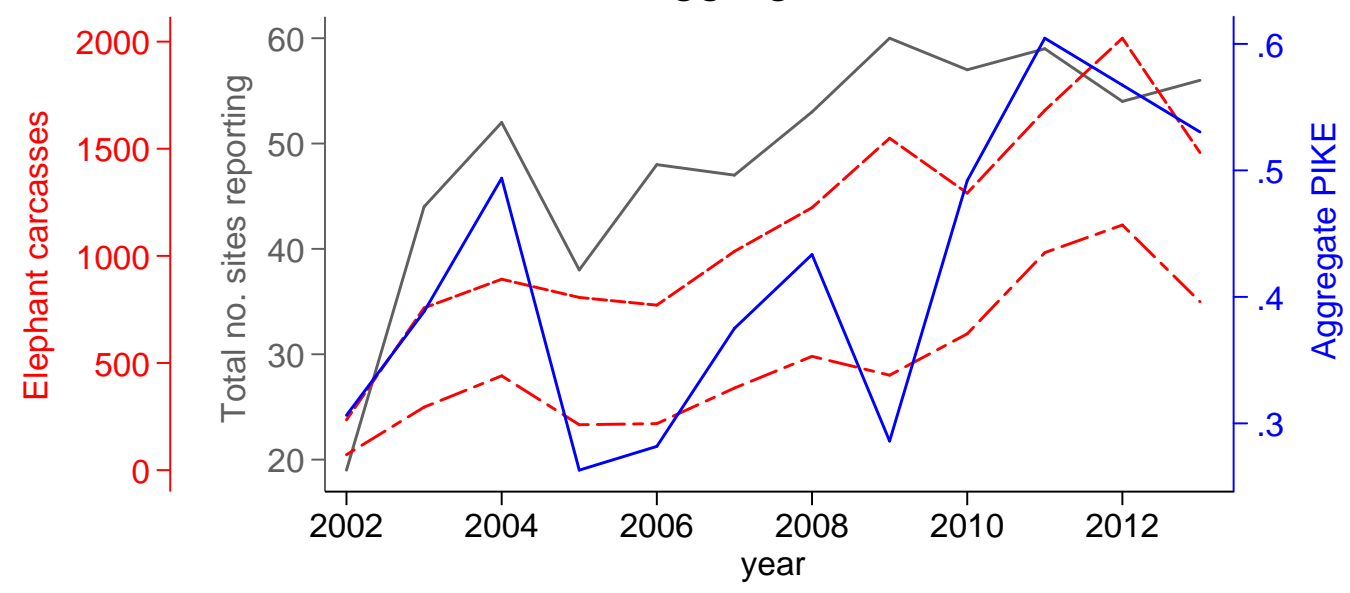

B

\section{Removing two 2009 outlier sites in Kenya and one 2012 outlier site in Botswana}

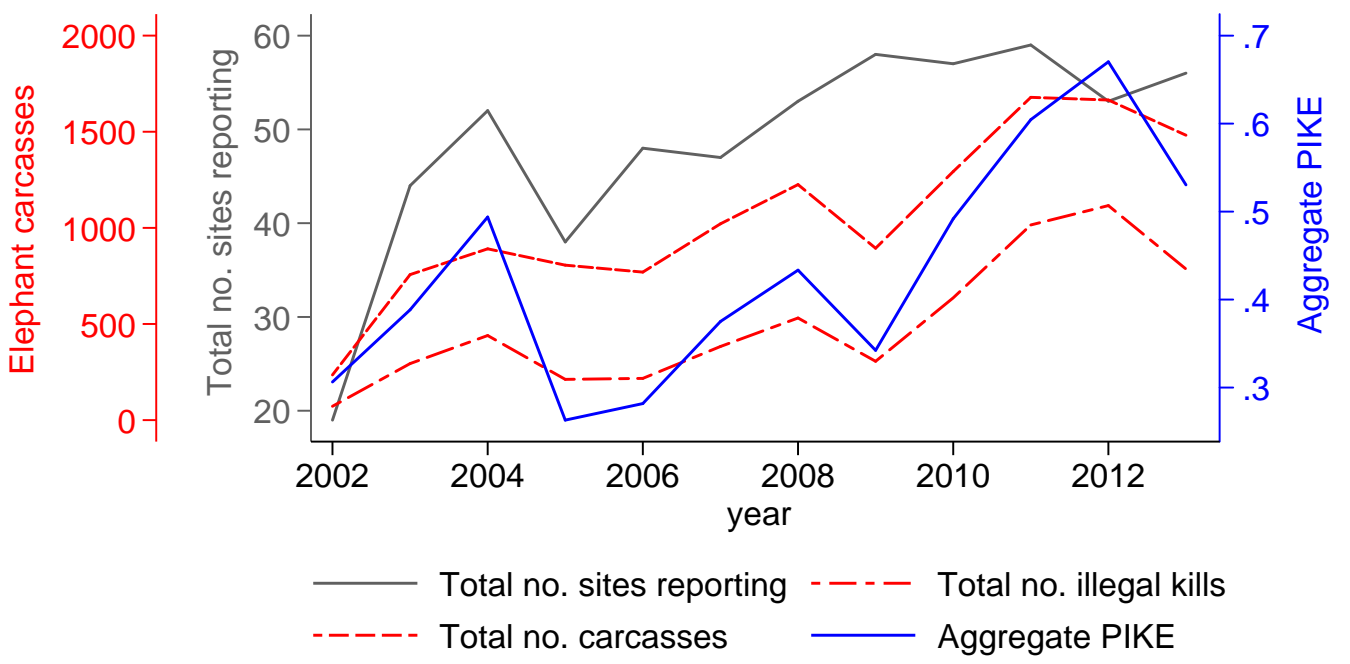

Appendix Figure A10: Declines in 2009 aggregate PIKE are driven by two outlying observations. The total number of sites reporting any elephant carcasses in MIKE data (grey line) used to compute aggregate PIKE statistics analyzed in prior studies. Global aggregate PIKE (blue line) is the total number of illegally killed elephant carcasses discovered (red dot-dashed line) divided by the total number of carcasses discovered (red dashed line). (A) Prior studies observed that aggregate PIKE declined sharply in 2009 following the legal sale of ivory. This drop does not reflect a correspondingly rapid drop in illegally killed elephants, but rather is driven by a rise in total carcasses. This abrupt rise in total carcasses is driven entirely by two sites in Kenya that report extremely high rates of legal elephant mortality in 2009 ( $>9 \sigma$ outliers, see Figure A2), which are dropped from our main analysis. (B) When these two outlier observations are removed from the sample (see Appendix B for details), aggregate total mortality falls (rather than rises) in 2009 and the associated drop in aggregate PIKE appears similar to background variability. 
which is plotted as the blue line in Figure A10A. It has been noted (Burn, Underwood, and Blanc, 2011) that this aggregated measure declined in 2009, just after the legal sale was delivered to China, but it would be incorrect to infer that this observation is at odds with our main result. Most of the change in aggregate PIKE is driven by an increase in legal elephant mortality observed in 2009, since total illegal killing declined very modestly (Figure A10A, red lines). Inspection of the data (Figure A2) indicates that this increase in legal mortality is driven by two outlying observations from sites in Kenya that experienced extreme drought that year (Burn, Underwood, and Blanc, 2011). When those two outlying observations are removed, the sharp drop in PIKE essentially vanishes (Figure A10B). These two outlying observations are removed in the analysis presented in the main text. However, we demonstrate in Figure A1 that even if these outliers are included in our analysis, they are dramatically less influential because of the panel approach we adopt and do not generate a similar artifact in our estimates.

There are four additional reasons to prefer the panel approach we use (Equation 5-7), rather than examining aggregated global statistics (Equation 10). First, in the panel approach, local illegal killing is always normalized by local total mortality. In the aggregated data, measures of illegal killing are normalized by global total mortality, however global trends may not reflect idiosyncratic local events that increase the likelihood of observing illegal carcasses locally. Second, the panel approach allows us to account for unobserved local heterogeneity in both average poaching levels and local trends, which may be different across locations. Third, our panel of data is unbalanced, so some sites either stop reporting or begin reporting (or both) during the period of observation. If these sites differ from the average site, then their appearance or disappearance in the data will bias aggregate PIKE statistics but will not bias a panel model including site fixed effects. Fourth, the disaggregated approach allows us to examine spatial heterogeneity in effects, as is done in Figures 4.

Finally, we note that aggregated PIKE, which is used widely in conservation policy analysis, appears not to be well constructed for analysis even in the absence of legal mortality outliers. Unlike site-level PIKE, aggregate PIKE does not have the property of being purged of the effects of fluctuating elephant populations or surveyor search effort, two important unobserved factors. See Footnote 8 in the main text for a derivation of how these confounding effects are removed by the PIKE measure in site-level data. Because of the summation in the denominator of the aggregate PIKE measure, surveyor effort and elephant populations in each location do not cancel out. To see this, suppose there are only two locations $i=1$ and $i=2$. Then using the same notation as in Footnote 8 , by simple substitution we 
have:

$$
\begin{aligned}
& \text { Aggregate_PIKE }(i=\{1,2\}) \\
& =\frac{\sum_{i=1}^{2} \text { illegal_carcasses }_{i}}{\sum_{i=1}^{2} \text { total_carcasses }_{i}} \\
& =\frac{\text { illegal_carcasses }_{1}+\text { illegal_carcasses }_{2}}{\text { total_carcasses }_{1}+\text { total_carcasses }_{2}} \\
& =\frac{\text { population }_{1} \times \operatorname{Pr}\left(\text { illegal_death }_{1} \times f\left(\text { search_effort }_{1}\right)+\text { population }_{2} \times \operatorname{Pr}\left(\text { illegal_death }_{2} \times f\left(\text { search_effort }_{2}\right)\right.\right.}{\text { population }_{1} \times \operatorname{Pr}(\text { death })_{1} \times f\left(\text { search_effort }_{1}\right)+\text { population }_{2} \times \operatorname{Pr}\left(\text { death }_{2} \times f\left(\text { search_effort }_{2}\right)\right.} \\
& =\frac{\text { population }_{1} \times \operatorname{Pr}\left(\text { illegal_death }_{1} \times f\left(\text { search_effort }_{1}\right)\right.}{\text { population }_{1} \times \operatorname{Pr}\left(\text { death }_{1} \times f\left(\text { search_ef fort }_{1}\right)+\text { population }_{2} \times \operatorname{Pr}\left(\text { death }_{2} \times f\left(\text { search_effort }_{2}\right)\right.\right.}
\end{aligned}
$$

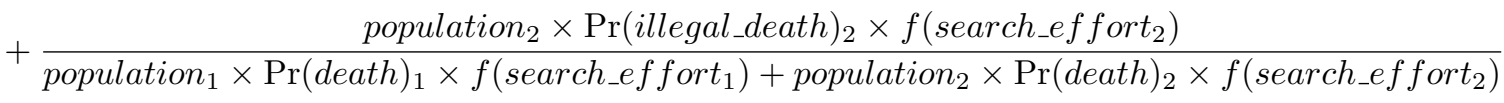

Which cannot be simplified further. This sum is a complex mathematical object with no clear interpretation for policy analysis. Suppose location 1 is Ghana and location 2 is Botswana. Then Aggregate_PIKE for the pair is the sum of total mortality in Ghana, divided by functions of elephant populations in both Ghana and Botswana as well as surveyor effort in both Ghana and Botswana, plus total mortality in Botswana, divided by functions of by elephant populations in both Ghana and Botswana as well as surveyor effort in both Ghana and Botswana. We see no plausible reason that one would want to divide total recorded elephant mortality in Ghana by elephant populations or surveyor effort in Botswana. Rather than removing confounding influences of local elephant populations and local surveyor effort (as PIKE was designed to do), Aggregate_PIKE introduces new confounding influences of elephant populations and surveyor effort at distant locations (without removing the local confounding effects). Our best guess is that Aggregate_PIKE came into common use as a measure for policy analysis because the useful properties of PIKE computed locally (i.e. removing confounding influences of elephant population and surveyor effort) seemed appealing and seemed like they ought to apply to Aggregate_PIKE as well. They do not. 